\title{
cAMP-Induced Expression of Neuropilin1 Promotes Retinal Axon Crossing in the Zebrafish Optic Chiasm
}

\author{
Alison L. Dell, ${ }^{1}$ Emma Fried-Cassorla, ${ }^{1}$ Hong Xu (徐洪), ${ }^{1,2}$ and Jonathan A. Raper ${ }^{1}$ \\ ${ }^{1}$ Department of Neuroscience, Perelman School of Medicine at the University of Pennsylvania, Philadelphia, Pennsylvania 19104, and ${ }^{2}$ Institute of Life \\ Science, Nanchang University, Nanchang 330031, China
}

Growing axons navigate a complex environment as they respond to attractive and repellent guidance cues. Axons can modulate their responses to cues through a G-protein-coupled, cAMP-dependent signaling pathway. To examine the role of G-protein signaling in axon guidance in vivo, we used the GAL4/UAS system to drive expression of dominant-negative heterotrimeric G-proteins (DNG) in retinal ganglion cells (RGCs) of embryonic zebrafish. Retinal axons normally cross at the ventral midline and project to the contralateral tectum. Expression of DNG $\alpha_{\mathrm{S}}$ in RGCs causes retinal axons to misproject to the ipsilateral tectum. These errors resemble misprojections in adcy1, adcy8, nrp1a, sema3D, or sema3E morphant embryos, as well as in sema3D mutant embryos. nrp1a is expressed in RGCs as their axons extend toward and across the midline. sema3D and sema3E are expressed adjacent to the chiasm, suggesting that they facilitate retinal midline crossing. We demonstrate synergistic induction of ipsilateral misprojections between $a d c y 8$ knockdown and transgenic DNG $\alpha_{\mathrm{S}}$ expression, adcy 8 and nrpla morphants, or nrpla morphants and transgenic DNG $\alpha_{\mathrm{S}}$ expression. Using qPCR analysis, we show that either transgenic $\mathrm{DNG} \alpha_{\mathrm{S}}$-expressing embryos or adcy8 morphant embryos have decreased levels of $n r p 1 a$ and $n r p 1 b$ mRNA. Ipsilateral misprojections in adcy 8 morphants are corrected by the expression of an $n r p 1 a$ rescue construct expressed in RGCs. These findings are consistent with the idea that elevated cAMP levels promote Neuropilin la expression in RGCs, increasing the sensitivity of retinal axons to Sema3D, Sema3E, or other neuropilin ligands at the midline, and consequently facilitate retinal axon crossing in the chiasm.

\section{Introduction}

The assembly of functional neural circuits during development requires that neurons interconnect with great specificity. The motile structure at the tip of the growing axon, the growth cone, interprets a constellation of permissive, attractive, and repellent cues that guide it to its target (Tessier-Lavigne and Goodman, 1996). Specific receptors that decorate the surface of a growth cone determine how it responds to the guidance cues it encounters. G-Protein-coupled receptors (GPCRs) are specialized to detect a wide variety of signals in the extracellular environment. Therefore, they are appealing candidates to direct axonal pathfinding. GPCRs are key mediators of chemotactic behavior. Examples include the cAMP sensor in the amoeboid slime mold dictostylium and chemokine receptors on leukocytes and migrating germ cells (Klein et al., 1988; Bleul et al., 1996; Knaut et al.,

Received Jan. 15, 2013; revised May 9, 2013; accepted May 21, 2013.

Author contributions: A.L.D., H.X., and J.A.R. designed research; A.L.D., E.F.-C., and H.X. performed research; A.L.D., E.F.-C., H.X., and J.A.R. analyzed data; A.L.D. and J.A.R. wrote the paper.

This work was supported by National Institutes of Health Grants R01-DA025407 (J.A.R.) and T32 EY-703532 (A.L.D.), and National Natural Science Foundation of China Grants 31171044 and 81160144 (H.X.). We thank Greg Bashaw and Michael Granato for comments on this manuscript and members of the Raper, Granato, and Bashaw laboratories for helpful discussions. We particularly thank Alemji Taku and Christina Marcaccio for their time and generosity in providing sema3D mutants for analysis.

The authors declare no competing financial interests.

Correspondence should be addressed to either of the following: Hong Xu, Institute of Life Science, Nanchang University, Nanchang 330031, China, E-mail: xuhong@ncu.edu.cn; or Jonathan A. Raper, Department of Neuroscience, Perelman School of Medicine at the University of Pennsylvania, 1115 BRB2/3, 421 Curie Boulevard, Philadelphia, PA 19104, E-mail: raperj@mail.med.upenn.edu.

DOI:10.1523/JNEUROSCI.0197-13.2013

Copyright $\odot 2013$ the authors $\quad 0270-6474 / 13 / 3311076-13 \$ 15.00 / 0$
2003). GPCRs are prevalent in the nervous system, including metabotropic neurotransmitter receptors expressed by neurons and odorant receptors in the olfactory epithelium. Odorant receptor-dependent cAMP signaling is critical for olfactory sensory neurons to reach their appropriate glomerular targets (Imai et al., 2006; Chesler et al., 2007). The metabotropic $\mathrm{GABA}_{\mathrm{B}}$ receptor mediates axonal repulsion in vitro (Xiang et al., 2002), and the metabotropic serotonin receptors $5-\mathrm{HT}_{1 \mathrm{~B}}$ and $5-\mathrm{HT}_{1 \mathrm{D}}$ modulate thalamic axon responses to netrin 1 by inhibiting cAMP production (Bonnin et al., 2007). Sdf1 signaling through the GPCR CXCR4, or glutamate signaling through the metabotropic receptor $\mathrm{mGluR} 1$, antagonize axonal repellents in vitro (Chalasani et al., 2003; Kreibich et al., 2004). Although GPCRs are appealing candidate axon guidance receptors, little is known about their role in axonal pathfinding in the intact developing nervous system.

Our objective was to test the contributions of GPCR and G-protein-mediated signaling to axon pathfinding in vivo. To this end, we generated transgenic zebrafish lines expressing dominant-negative (DN) constructs targeting GPCR effectors, namely the heterotrimeric G-proteins $\mathrm{G} \alpha_{\mathrm{i} / \mathrm{o}}, \mathrm{G} \alpha_{\mathrm{q} / 11}, \mathrm{G} \alpha_{\mathrm{s} / \mathrm{olf}}$, and $\mathrm{G} \beta \gamma$. These DN reagents were specifically expressed in retinal ganglion cells (RGCs) to examine their effect on retinal pathfinding. In zebrafish, RGC axons exit the eye, cross at the ventral midline at the optic chiasm, and then project dorsally and posteriorly to the contralateral tectum and other target locations.

We find that the expression of DN constructs targeting $\mathrm{G} \alpha$, $\mathrm{G} \alpha_{\mathrm{q}}$, or $\mathrm{G} \beta \gamma$ induce infrequent and minor errors in retinal projections. Expression of a DN construct targeting $\mathrm{G} \alpha_{\mathrm{S} / \mathrm{olf}}\left(\mathrm{DNG} \alpha_{\mathrm{S}}\right)$ 
induces significant ipsilateral tectal misprojections. These errors phenocopy knockdown of the calcium/calmodulin-activated adenylate cyclase 1 (adcy1) or adcy8 (Xu et al., 2010). Our findings suggest that cAMP levels can regulate midline crossing of RGC axons. Similar ipsilateral misprojections are observed after knocking down semaphorin3D (sema3D) or semaphorin3E (sema3E), axonal guidance cues expressed at the ventral midline, or the semaphorin receptor component neuropilin1a (nrpla), which is expressed in RGCs. Here we show that ipsilateral misprojections induced in retinal axons with impaired cAMP signaling can be ascribed to a concomitant reduction of nrp1 expression. We propose that GPCR-mediated elevation of cAMP levels promotes the expression of $n r p 1$ in RGCs, sensitizes retinal axons to Nrp1 ligands, including sema3D and sema3E expressed at the midline, and thereby promotes retinal axon crossing.

\section{Materials and Methods}

Generation of DN constructs. DNG $\alpha$ subunit constructs were generated by backtranslation of the C-terminal 11 aa sequences of individual $\alpha$ subunits following Gilchrist et al. (1999). The 5' primer included Pst1 and a Kozak sequence, whereas the $3^{\prime}$ primer included a stop and a NotI site. Primers encoding the DN peptides were annealed and cloned into the Pst1/Not1 sites in Tol2 dual UAS vector: UAS:MCS;UAS:GAP43citrine (Balciunas et al., 2006; Lakhina et al., 2012). The DN $\beta \gamma$, GRK-CT (G-protein-coupled receptor kinase, C-terminal fragment) in pcDNA3, was a gift from the Albert laboratory (McGill University, Montreal, QC, Canada) (Ghahremani et al., 1999). The plasmid was digested with Not1/ HindIII, and the resulting $1.5 \mathrm{~kb}$ fragment was ligated into the Tol2 dual UAS vector (Lakhina et al., 2012).

Generation of Tol2;Atonal7:Gal4-VP16pA. Seven kilobases $5^{\prime}$ to Atonal 7 (Ath7) (previously Ath5) promoter was cut from pAth5:eGFP (a gift from Chi-Bin Chien, University of Utah, Salt Lake City, UT) with BamH1. This fragment was cloned into the BglII site of the Tol2 plasmid (Balciunas et al., 2006). The Gal4-VP16-pA cassette with Notl sites flanking the target sequence was generated by PCR. The product was cloned into TOPOII and digested with NotI to generate a $935 \mathrm{bp}$ fragment. The fragment was cloned into the NotI site of the Tol2 Ath7 promoter-containing plasmid to generate Ath7:Gal4.

Establishment of zebrafish transgenic lines. One-cell stage embryos were injected with Gal4 or UAS Tol2 constructs and raised to adulthood. Founders were identified by crossing to appropriate reporter lines. Two or more independent lines were generated for each UAS or Gal4 construct (Lakhina et al., 2012). Fluorescent F1 progeny were raised to adulthood and crossed to wild type (WT). Subsequent generations of UAS or Gal4 embryos were raised and genotyped by PCR for citrine (UAS lines), Gal4, or by screening for fluorescent fish after crossing to reporter lines. Lines have been assigned in the zebrafish database as follows: Ath7:Gal4:VP16: Tg(atoh7:Gal4-VP16)p203; UAS:dnG $\alpha$ i1/2;UAS: citrine: $\operatorname{Tg}(14 x \mathrm{xAS}$ :dngnai,GAP-citrine)p204; UASdnG $\alpha \mathrm{q} / 11$; UAS:citrine: $\operatorname{Tg}(14 x U A S:$ dngnaq,GAP-citrine)p205; UAS:dnG $\beta \gamma$; UAS:citrine: $\operatorname{Tg}(14 x U A S$ : Mdo.Adrbk1,GAP-citrine)p207; UASdnG $\alpha$ S/olf;UAS:citrine: $\mathrm{Tg}(14 \mathrm{xUAS}$ :dngnas,GAP-citrine)p206; UAS:citrine: $\operatorname{Tg}(14 x U A S: G A P-c i t r i n e) p 201$, and UAS: nrpla;UAS:citrine: $\operatorname{Tg}(14 \mathrm{xUAS}$ :nrpla,GAP-citrine)p208.

Zebrafish maintenance. Zebrafish (Danio rerio) were raised and maintained under standard conditions (Mullins et al., 1994). Zebrafish embryos of either sex were staged by time after fertilization and/or morphology (Kimmel et al., 1995). Transgenic lines and mutant used in this study include the following: (1) Isl2b:GFP $\mathrm{Tg}(-17.6$ isl2b:GAPGFP)zc20 (Pittman et al., 2008); (2) Isl2b:mCherry $\mathrm{Tg}(-17.6$ isl2b: mCherry-HsHRAS)zc25 (Pittman et al., 2008); (3) s11olt:Gal4 Et(e1b: GAL4-VP16)s11olt (Scott and Baier, 2009); and (4) UAS:citrine $\operatorname{Tg}$ (14xUAS:GAP-citrine)p201zf360 (Lakhina et al., 2012). sema3D ${ }^{\text {sal661 }}$ and $\operatorname{nrp} 1 a^{\text {sal } 485}$ mutants were obtained through the Zebrafish Mutation Project (Sanger Center, Cambridge, UK). Otherwise, experiments were performed in Tübingen or Tübingen Long Fin WT fish maintained in the fish facility at the University of Pennsylvania (Philadelphia, PA). Fish were mated to produce embryos for in situ hybridization, morpholino
(MO) injections, and in vitro cell culture. Embryos were raised in 1XE3 embryo medium (in mM: $5 \mathrm{NaCl}, 0.17 \mathrm{KCl}, 0.33 \mathrm{CaCl}_{2}$, and $0.33 \mathrm{MgSO}_{4}$ in deionized water), with $0.006 \%$ phenylthiourea added at $24 \mathrm{~h}$ to suppress pigmentation.

Whole-mount immunostaining. Immunostaining was performed as described previously (Chalasani et al., 2007). Larval zebrafish were fixed overnight with $4 \%$ paraformaldehyde in PBS, followed by methanol dehydration and permeabilization in ice-cold acetone. Primary and secondary antibodies were used at the following concentrations to visualize GFP-positive cells and axons: 1:500 goat anti-GFP (Rockland Immunochemicals), 1:500 anti-goat IgG Alexa Fluor 488 (Invitrogen), 1:500 antirabbit IgG Alexa Fluor 546 (Invitrogen), and 1:500 anti-mouse IgG Alexa Fluor 546 (Invitrogen). Immunostained larvae were imaged using Leica TSP2 or TSP 5 confocal microscopes.

Eye fills. Lipophilic dyes were used to orthogradely label RGC axons as described by Xu et al. (2010). Briefly, fixed 5 d postfertilization (dpf) larvae were mounted in $1.2 \%$ agarose on glass slides. Retinae were pressure injected with either DiI or DiD (both from Invitrogen) dissolved in dimethylformamide. Dyes were allowed to diffuse overnight at room temperature or for $3 \mathrm{~h}$ at $28.5^{\circ} \mathrm{C}$. Dye-labeled retinotectal axons were imaged using Leica TSP2 or TSP5 confocal microscopes and are displayed as maximum projected $z$-stacks.

In situ hybridization. Single-label in situ hybridization was performed as described by Chalasani et al. (2007), and double-label in situ hybridization was performed as described by Brend and Holley (2009). Digoxigenin (DIG)-labeled antisense mRNA riboprobes were used to visualize RNA location. After probe application and incubation, anti-DIG-horseradish peroxidase (POD) or anti-fluorescien-POD (Roche) was applied, followed sequentially by fluorescein-coupled tyramide and cyanine 3 -coupled tyramide to amplify the fluorescent signals (PerkinElmer Life and Analytical Science). Fish were then immunostained to visualize GFP-positive cells. pBSSKII+ nrp1a (RefSeq accession number NM_001040326) probe construct targeting nucleotides 1761-2760 was a kind gift from Wattaru Shoji (Tohoku University, Sendai, Japan). Semaphorin probes were as follows: pCRII sema3D (RefSeq accession number NM_131048), nucleotides 1810-2566; and pCRII sema3E (RefSeq accession number NM_001045084), nucleotides $2200-3020$.

$m R N A$ injections. A Glu-Glu tagged constitutively active $\mathrm{G} \alpha_{\mathrm{S}}\left(\mathrm{caG} \alpha_{\mathrm{S}}\right.$; Q227L) construct was obtained from the Missouri Science and Technology cDNA Resource Center (Rolla, MO). mRNAs were generated using the mMessage mMachine kit and poly(A) tailing kit (Ambion). Protein production from injected mRNA was confirmed by immunohistochemistry using mouse anti-Glu-Glu antibody (Abcam).

Morpholino injections. Morpholinos targeting exons 3 and 4 of adcy 8 were injected as described by $\mathrm{Xu}$ et al. (2010). Sema3D translationblocking sema3D MO1 (CATGATGGACGAGGAGATTTCTGCA) and splice-blocking sema3D MO2 (CACATTCAGTCTGCAGCAAGAGAAA) MOs were described previously (Berndt and Halloran, 2006). We designed two sema3E splice blocking MOs, one targeting exon 5, sema3E MO1 (TTGTAGAGATGAACACTTACGGTAG), and one targeting exon 8, sema3E MO2 (AAAGAGTGAAGCTCCCCTACCGAGC), both of which are predicted to alter the reading frame and induce an early termination of the encoded peptide. Nrpla MO1 (GAATCCTGGAGT TCGGAGTGCGGAA) blocks translation as described previously by Lee (2002). Nrp1a MO2 (AATGTTTTTTCCTTACCCGTTTTGA) targets the splice junction between exons 2 and 3. Sema3A1 (CTTGTAGCCCAC AGTGCCCAGAGCA) and P53 (GCGCCATTGCTTTGCAAGAATTG) MOs were described previously (Shoji et al., 2003; Robu et al., 2007). Synergistic interactions between MOs were assessed using a simple Monte Carlo-based simulation that estimates the probability that two different manipulations are independent and additive when combined.

Electroporations were performed according to Hendricks and Jesuthasan (2007). Anesthetized $24 \mathrm{~h}$ postfertilization (hpf) embryos were singly embedded in drops of $1.2 \%$ low-melting agarose (catalog \#50302 SeaPrep) containing $\sim 0.016 \%$ tricaine in electroporation Ringer's solution (in mM: $180 \mathrm{NaCl}, 5 \mathrm{KCl}$, and $1.8 \mathrm{CaCl}_{2}$ ). DNA solutions containing $H u C: G a l 4-V P 16$ and either control or UAS:nrpla rescue constructs were coinjected into one eye and electroporated using a BTX ECM830 
square-wave electoporator set to deliver five 1-ms pulses at $30 \mathrm{~V}$. The $H u C: G a l 4-V P 16$ plasmid was described previously (Hendricks and Jesuthasan, 2007). Nrp1a was first cloned into PCR2.1 and subsequently cloned into the dual UAS vector using EcoRV and NheI sites. After electroporation, embryos recovered in E3 medium and were fixed at 3 or 4 dpf for analysis. Embryos were immunostained for GFP, and axonal projections were evaluated for ipsilateral or contralateral projections by confocal microscopy. To better visualize labeled cell bodies and axonal projections in the electroporated embryos displayed in Figure 4, nonspecific background staining was selectively removed from individual optical sections that were out of the plane of focus for retinal processes using NIH ImageJ. Maximum projections were then produced from stacks of all the sections together.

Quantitative PCR. UAS:DNG $\alpha_{\mathrm{S}}$ transgenics were crossed to s1101t: Gal4 fish (Scott and Baier 2009) to drive pan-neuronal expression of $\mathrm{DNG} \alpha_{\mathrm{S}}$. Embryos were dissected into heads and tails, heads were stored in RNAlater (Ambion), tails were processed using HotShot, and UAS copy number was assessed in the tail material by SYBR Green (Sigma) quantitative PCR (qPCR) for genomic citrine (5'-GCCCCGTGCTGCTG CCCGAC-3'; 5'-CCCGGCGGCGGTCACGAACT-3'), using a $\Delta \Delta \mathrm{ct}$ comparison with EF1A (5'GGCAGACCGTTGCTGTCGGCG-3'; 5' -GG TTGGGAAGAACACGCCGCAACCT- $3^{\prime}$ ) as an endogenous internal control (Bae et al., 2011). Embryo heads were then pooled by estimated copy number. RNA was extracted with Trizol (Sigma) and used to make cDNA using the SuperScript kit (Invitrogen). qPCR was performed on cDNA from pooled embryos using SYBR Green for $n r p 1 a$ (5' -GCCCAA ACATGGACCACACAGGCGG-3'; $5^{\prime}$-CCTGGCCCGACACCGACGGA C-3'), cxcr4 (5'-GGCGGTCGATGCAGTCAGCGGG-3'; 5'-GCGGTC CAGGCTGATGAATCGCAGG-3'), and EF1A (5'-GGGGAGCAGCAG CTGAGGAGTGA-3'; 5' -AGGAGCCCTTGCCCATCTCAGCG-3'). Expression levels of pooled fluorescent and nonfluorescent sibling controls with and without MO treatment were compared using a two-tailed Student's $t$ test.

Eye removal for optic tract degeneration. Ath7:Gal4 fish were crossed to either control UAS:citrine (Lakhina et al., 2012) or UAS:nrpla (rescue) transgenics. Resulting progeny were injected with adcy $8 \mathrm{MO}$ at the onecell stage and allowed to develop to $3 \mathrm{dpf}$. Anesthetized citrine-positive fish were mounted in 1\% low-melting agarose prepared in E3 medium, and one eye was removed using sharpened Tungsten needles. Fish were allowed to recover in E3 medium and returned to the incubator for $48 \mathrm{~h}$ to allow optic tract degeneration. Fluorescent axons from the intact eye were then imaged and assessed for ipsilateral or contralateral projections. Statistical comparisons were made using Fisher's exact test.

\section{Results}

RGCs expressing DNG $\alpha_{\mathrm{S}}$ misproject to the ipsilateral tectum Activated GPCRs signal through heterotrimeric G-proteins composed of $\alpha, \beta$, and $\gamma$ subunits. During activation, GPCRs act as guanine nucleotide exchange factors, which promote the exchange of GDP to GTP on the $\alpha$ subunit, prompting dissociation of the heterotrimer into an active GTP-bound $\alpha$ subunit and the $\beta \gamma$ complex. There are four families of $\mathrm{G} \alpha$ subunits: $\mathrm{G} \alpha_{\mathrm{i}}, \mathrm{G} \alpha_{\mathrm{q}}$, $\mathrm{G} \alpha_{\mathrm{S}}$, and $\mathrm{G} \alpha_{12 / 13}$. Each $\mathrm{G} \alpha$ triggers specific downstream signaling events (Oldham and Hamm, 2008). G $\alpha_{\mathrm{S}}$ is named for its ability to stimulate ADCYs to produce cAMP, $\mathrm{G} \alpha$ i canonically inhibits ADCY production of cAMP, whereas $\mathrm{G} \alpha_{\mathrm{q}}$ and the $\mathrm{G} \beta \gamma$ complex can promote calcium signaling through PLC (Downes and Gautam, 1999; Oldham and Hamm, 2006). We previously identified a G-protein-coupled calmodulin, cAMP, and PKAdependent pathway that reduces axonal response to repellents (Chalasani et al., 2003; Kreibich et al., 2004). Sdf1 signaling through the GPCR CXCR4 abrogates the repellent effect of Slit2 on cultured retinal axons. This pathway signals through $\mathrm{G} \alpha_{\mathrm{i}}$, $\mathrm{G} \alpha_{\mathrm{q}}$, and $\beta \gamma$ subunits (Twery and Raper, 2011). These findings led us to consider whether GPCRs might act more generally as axon guidance receptors.
To test the contribution of G-protein-coupled signaling to axon guidance in vivo, we generated and expressed DN constructs targeting $\mathrm{G} \alpha$ subunits $\alpha_{\mathrm{i} / \mathrm{o}}, \alpha_{\mathrm{q} / 11}$, and $\alpha_{\mathrm{s} / \mathrm{olf}}$ (Gilchrist et al., 1999, 2002). These constructs encode the last 11 aa of each $\mathrm{G} \alpha$ subunit. This $\mathrm{C}$-terminal sequence is divergent among the different $\mathrm{G} \alpha$ subunits and is essential for $\mathrm{G} \alpha$-specific heterotrimer binding to GPCRs (Gilchrist et al., 2002). The peptides act as competitive inhibitors of endogenous heterotrimers for binding to their cognate GPCRs (Fig. 1A; Gilchrist et al., 1999). We also generated a construct targeting the $\beta \gamma$ complex (Ghahremani et al., 1999). The DNG $\beta \gamma$ we used encodes the C-terminal fragment of an endogenous regulator of G-protein signaling, GRK-2 (Koch et al., 1994). The pleckstrin homology domain of GRK-2 binds and inactivates free G $\beta \gamma$ subunits and is sufficient to block dopamine-induced $\mathrm{Ca}^{2+}$ release in an in vitro assay (Ghahremani et al., 1999). We previously used the same $\mathrm{DNG} \alpha, \mathrm{DNG} \alpha$, and $\mathrm{DNG} \beta \gamma$ constructs in primary neuronal culture to block the Sdf1/CXCR4 signaling pathway (Twery and Raper, 2011).

We adapted this approach to examine the contribution of GPCR signaling to axonal pathfinding during normal development in the zebrafish embryo. G $\alpha$ terminal sequences are identical in the zebrafish and in higher vertebrates. DN constructs were cloned into a Tol2:UAS expression vector in which each construct is driven in tandem with GAP43-citrine, a membranetargeted fluorescent label suitable for the visualization of long axonal projections (Fig. 1B; Lakhina et al., 2012). Tol2 plasmids containing $\mathrm{DNG} \alpha_{\mathrm{i}}, \mathrm{DNG} \alpha_{\mathrm{q}}$, or DNG $\beta \gamma$ constructs were tested and found to block Sdf1-mediated anti-repellent signaling in chick DRG growth cones (data not shown), consistent with our previous findings (Twery and Raper, 2011). We generated an ath7 promoter-driven GAL4 line that we used to express UAScontaining constructs in RGCs. ath7 (previously ath5) is a bHLH transcription factor required for RGC neurogenesis and is expressed in retinal progenitors and RGCs (Kay et al., 2001; Vetter and Brown, 2001). We focused our analysis on the retinotectal projection because it is a well-established model of midline axon guidance and a system in which we previously showed that Sdf1 mediates antirepellent activity (Chalasani et al., 2007; Xu et al., 2010).

RGCs are first born in the ventronasal retina at $30 \mathrm{hpf}$ and extend axons out of the eye and through the optic stalk. They project ventrally, crossing the ventral midline to form the optic chiasm, before projecting dorsally and posteriorly to their synaptic targets in the tectum and arborization fields 1-9 (Burrill and Easter, 1994). Retinal axons first cross the midline at $\sim 36 \mathrm{hpf}$, sometimes making minor errors that are generally corrected by 3 $\mathrm{dpf}$ (Hutson and Chien, 2002). Retinal projections were visualized at $3 \mathrm{dpf}$ in $\mathrm{DNG} \alpha /$ citrine, $\mathrm{DN} \beta \gamma /$ citrine, or citrineexpressing embryos (Fig. $1 C, D$ ). We examined the frequency of ectopic misprojections. We also examined retinal projections from individual eyes by the orthograde transport of the lipophilic fluorescent tracers DiI or DiD injected into the eye at $5 \mathrm{dpf}$ (Fig. $1 E, F)$. This approach revealed many of the same errors that are apparent in the $3 \mathrm{dpf}$ preparations but could also detect ipsilateral misprojections to the incorrect tectum. Retinal projections were examined in transgenic lines from two independent founders for each DN construct.

The gross morphology of the eye is normal in Ath7:Gal4 and $\mathrm{DNG} \alpha$ - or $\mathrm{DN} \beta \gamma$-expressing embryos. RGC axons and some additional retinal cell types including photoreceptor neurons are fluorescently labeled (Fig. 1C). No errors are de- 

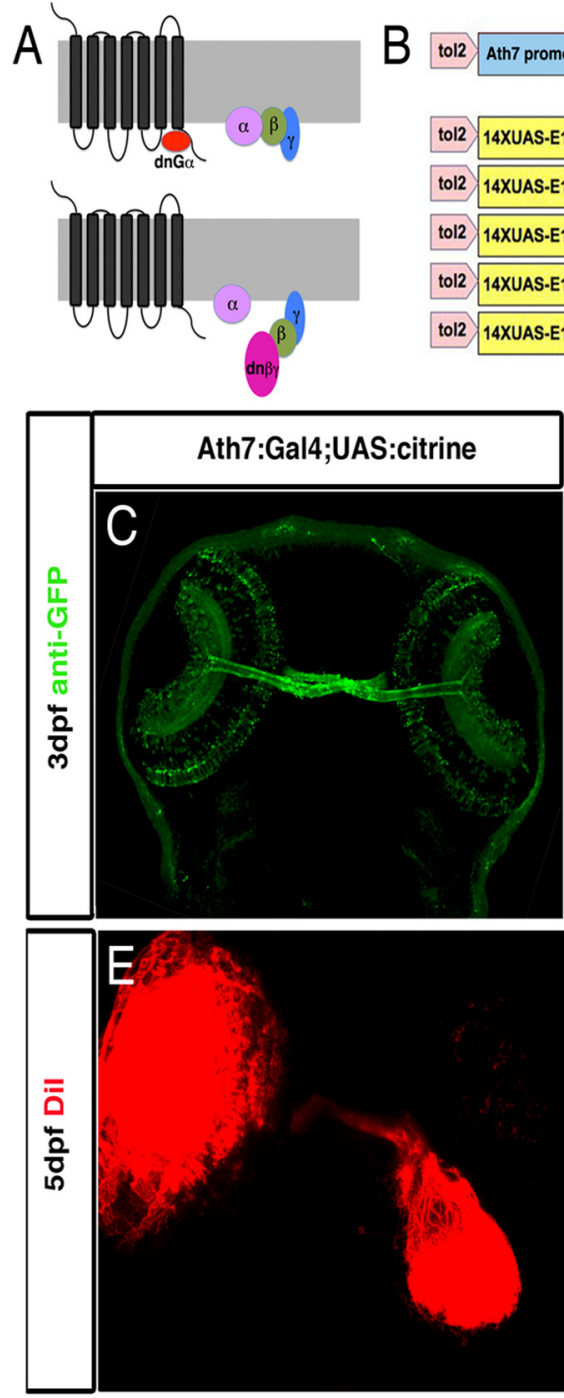
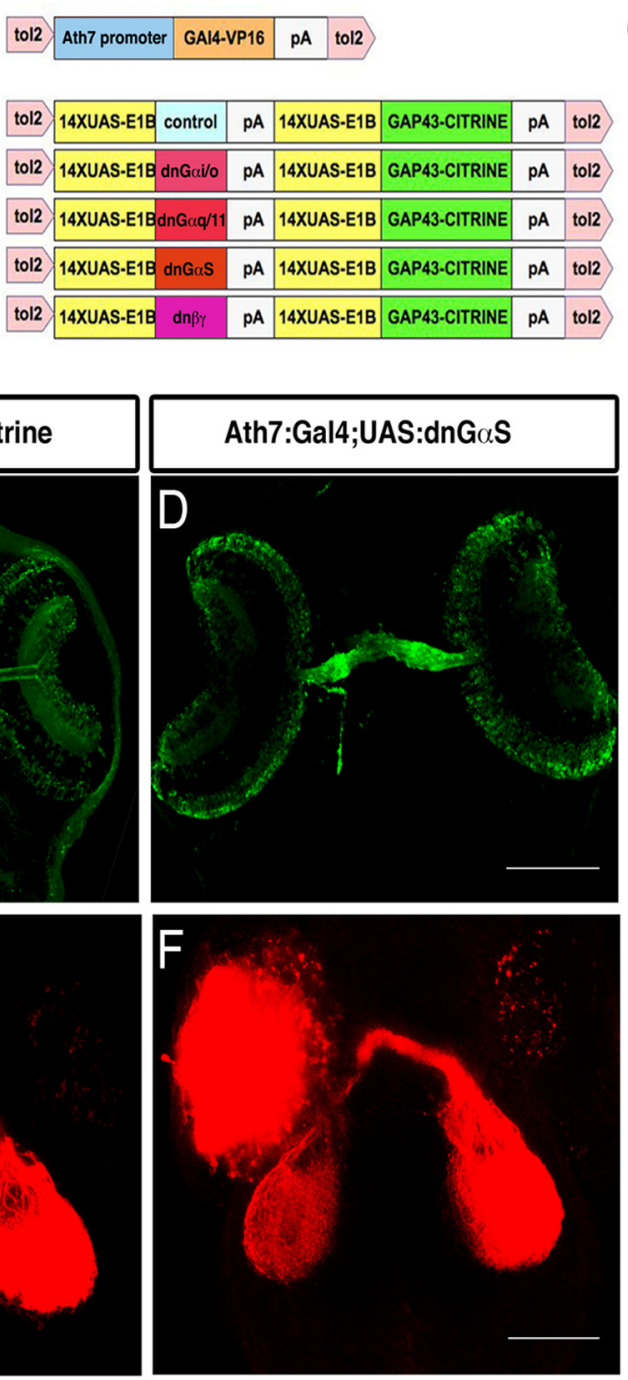
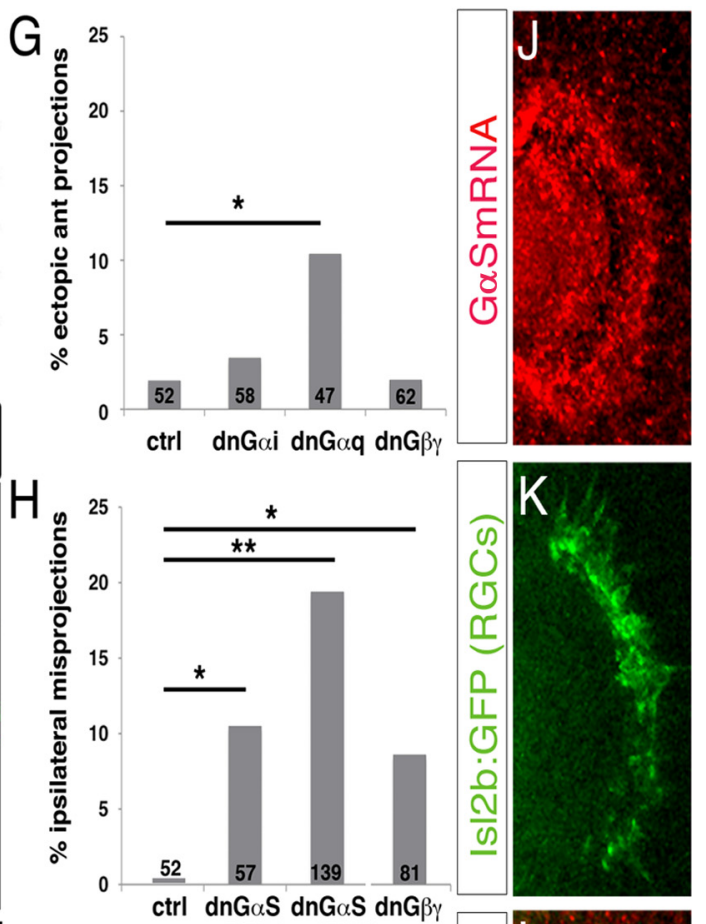
$1-2 X$ UAS 1-4X UAS

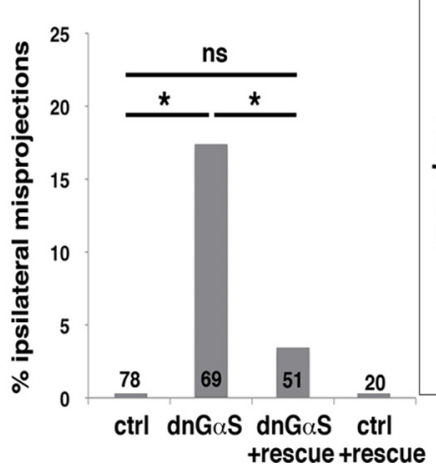

Figure 1. Retinal axons expressing $G \alpha_{s}$ misproject to the ipsilateral tectum. We generated multiple transgenic lines expressing DNG signaling reagents and expressed them in RGCS. $A$, The reagents block G-protein-coupled signaling by either $\alpha$-specific steric hindrance of trimeric G-protein binding to activated GPCRs or sequestering active $\beta \gamma$ subunits. $B$, Summary of constructs: the ath7 promoter drives expression of Gal4 in RGCS; UAS constructs drive both an axonal marker and DN reagents. $\boldsymbol{C}, \boldsymbol{E}$, RGC axons exit the eye and cross at the midline at the chiasm before projecting contralaterally to their synaptic targets in control embryos. $\boldsymbol{D}$, An ectopic ipsilateral misprojection of retinal axons visualized by citrine expression in a DNG $\alpha_{\mathrm{S}}$ transgenic embryo. $\boldsymbol{F}$, Filling one eye with lipophilic dye labels retinal axons extending within the optic tracts to both the ipsilateral and contralateral tecta of a DNG $\alpha_{5}$ transgenic embryo. Each retinal projection was scored as normal or aberrant, and the percentage of projections with errors are displayed. G, Quantification of ectopic anterior misprojections in control, DNG $\alpha_{\mathrm{i}^{-}}$, DNG $\alpha_{q^{-}}$, and DNG $\beta \gamma$-expressing RGCs. $\boldsymbol{H}$, There is an increase in percentage of retinal projections that include ipsilateral misprojections with increased expression of DNG $\alpha_{s}$. DNG $\beta \gamma$ also induces significant ipsilateral misprojections. I, A synthetic mRNA for a caG $\alpha_{S}$ rescues ipsilateral misprojections in DNG $\alpha_{S}$ expressing transgenic embryos. Quantification of ipsilateral misprojections in transgenics expressing multiple copies of DNG $\alpha_{s}$ or sibling controls not expressing DNG $\alpha_{s}$ with or without the $G \alpha_{s}$ rescue construct. $J-L$, In situ hybridization for $G \alpha_{s} \mathrm{mRNA}$ (red) was performed in 36 hpf Isl2b:GFP transgenic embryos in which a subset of RGCs express GFP. Ventral views of a 36 hpf eye demonstrate that $G \alpha_{S}$ (J, red) is expressed in $\mathrm{RGCs}\left(\boldsymbol{K}\right.$, green) at 36 hpf. ${ }^{*} p<0.05$, ${ }^{* *} p<0.01$ using Fisher's exact test. Scale bars: $\boldsymbol{C}-\boldsymbol{F}$, $100 \mu \mathrm{m} ; J-L, 50 \mu \mathrm{m}$. ctrl, Control.

tected in the exit of retinal axons from the eye in any condition. No significant errors are observed in embryos expressing $\mathrm{DNG} \alpha_{\mathrm{i}}$. Occasional ectopic anterior misprojections are observed in $\mathrm{DNG} \alpha_{\mathrm{q}^{-}}$expressing but not in $\mathrm{DNG} \alpha_{\mathrm{S}^{-}}, \mathrm{DNG} \alpha_{\mathrm{i}^{-}}$, or DNG $\beta \gamma$-expressing embryos (Fig. $1 G$ ). More strikingly, we observe ipsilateral misprojections of RGC axons expressing either $\mathrm{DNG} \beta \gamma$ or $\mathrm{DNG} \alpha_{\mathrm{S}}$ (Fig. $1 D, F, H$ ). Embryos containing multiple copies of the $\mathrm{DNG} \alpha_{\mathrm{S}}$ transgene have an increased penetrance of the ipsilateral misprojection phenotype (Fig $1 H$ ). Injection of a constitutively active (ca) capped mRNA encoding $\mathrm{caG} \alpha_{\mathrm{S}}$ (Q227L) rescues ipsilateral retinal misprojections of embryos expressing one to four copies of the $\mathrm{DNG} \alpha_{\mathrm{S}}$ transgene (Fig. $1 I$ ).
$\mathrm{G} \alpha_{\mathrm{S}}$ is transcribed from the imprinted GNAS locus, and long and short isoforms are expressed in temporally distinct patterns throughout the embryo (Krechowec et al., 2012). Although these isoforms vary at their $\mathrm{N}$ termini, they are indistinguishable in their ability to activate adenylyl cyclases (Novotny and Svoboda, 1998). The DNG $\alpha_{\mathrm{S}}$ we used targets both isoforms. To confirm expression of $\mathrm{G} \alpha_{\mathrm{S}}$ in the developing zebrafish retina, we performed in situ hybridization using a C-terminal directed probe that recognizes both long and short isoforms. We detect broad expression of $\mathrm{G} \alpha_{\mathrm{S}}$ as reported previously in other organisms ( $\mathrm{Li}$ et al., 2000). $\mathrm{G} \alpha_{\mathrm{S}}$ is expressed within the RGC layer at the time retinal axons cross 
the midline (Fig. $1 J-L$ ), consistent with previous RT-PCR-based expression studies in the adult zebrafish (Oka and Korsching, 2011). Our findings show that if $\mathrm{G} \alpha_{\mathrm{S}}$ activity is reduced in retinal neurons, then they make abnormal ipsilateral projections, and these errors are corrected if constitutive $\mathrm{G} \alpha_{\mathrm{s}}$ activity is expressed along with the $\mathrm{DNG} \alpha_{\mathrm{S}}$. We conclude that $\mathrm{G} \alpha_{\mathrm{S}}$ is required within RGCs for retinal axons to cross the midline normally.

Retinal misprojections in DNG $\boldsymbol{\alpha}_{\mathrm{S}}$ transgenics phenocopy adcy8, sema3D, sema3E, or nrp1a knockdown

We recently described a role for the calcium/ calmodulin-stimulated adenylyl cyclases $\mathrm{ADCY} 1 \mathrm{~b}$ and $\mathrm{ADCY} 8$ in promoting retinal midline crossing ( $\mathrm{Xu}$ et al., 2010). Knockdown of $a d c y 1 b$ or $a d c y 8$ produces ipsilateral retinal misprojections in $20-30 \%$ of morphant embryos, similar to transgenic embryos in which Ath7 drives more than one copy of $\mathrm{DNG} \alpha_{\mathrm{S}}$ (Fig. $2 A, B$; Xu et al., 2010). Ipsilateral retinal misprojections can also be induced by knocking down members of the class 3 semaphorin family of axon guidance cues or one of their key receptor components. In mouse, the semaphorin receptor component Nrp1 was recently shown to promote midline crossing in the optic chiasm in a VEGF-dependent manner (Erskine et al., 2011). Sema6D, NrCAM, and PlexinAl expressed at the ventral midline promote retinal axon crossing (Kuwajima et al., 2012). In zebrafish, knockdown of sema3D induces ipsilateral misprojections of retinal axons (Sakai and Halloran, 2006). Here we extend these findings to report that $n r p 1 a$, sema3D, and sema3E all cooperate to promote retinal midline crossing in zebrafish embryos. Morpholino-induced knockdown of nrp1a, sema3D, or sema3E each produce ipsilateral misprojections similar to those observed in Ath7 promoterdriven $\mathrm{DNG} \alpha_{\mathrm{S}}$ transgenics (Fig. 2A,C-E). These findings were replicated with two independent MOs for each target and all produced ipsilateral projections (Fig. 2G). Ipsilateral misprojections were also observed when any of the semaphorin- or neuropilin-directed MOs were combined with an MO that targets $\mathrm{p} 53$, which reduces off-target MO effects (Robu et al., 2007).

To test whether sema3D, sema3E, and nrp 1a work cooperatively, we performed pairwise injections with low doses of MOs to these targets. Morpholinos against sema3D and nrpla, sema3E and nrpla, or sema3D and sema3E all act synergistically, inducing more ipsilateral misprojections than predicted by summing the effects of each $\mathrm{MO}$ alone (Fig. $2 \mathrm{H}$ ). In contrast, MOs
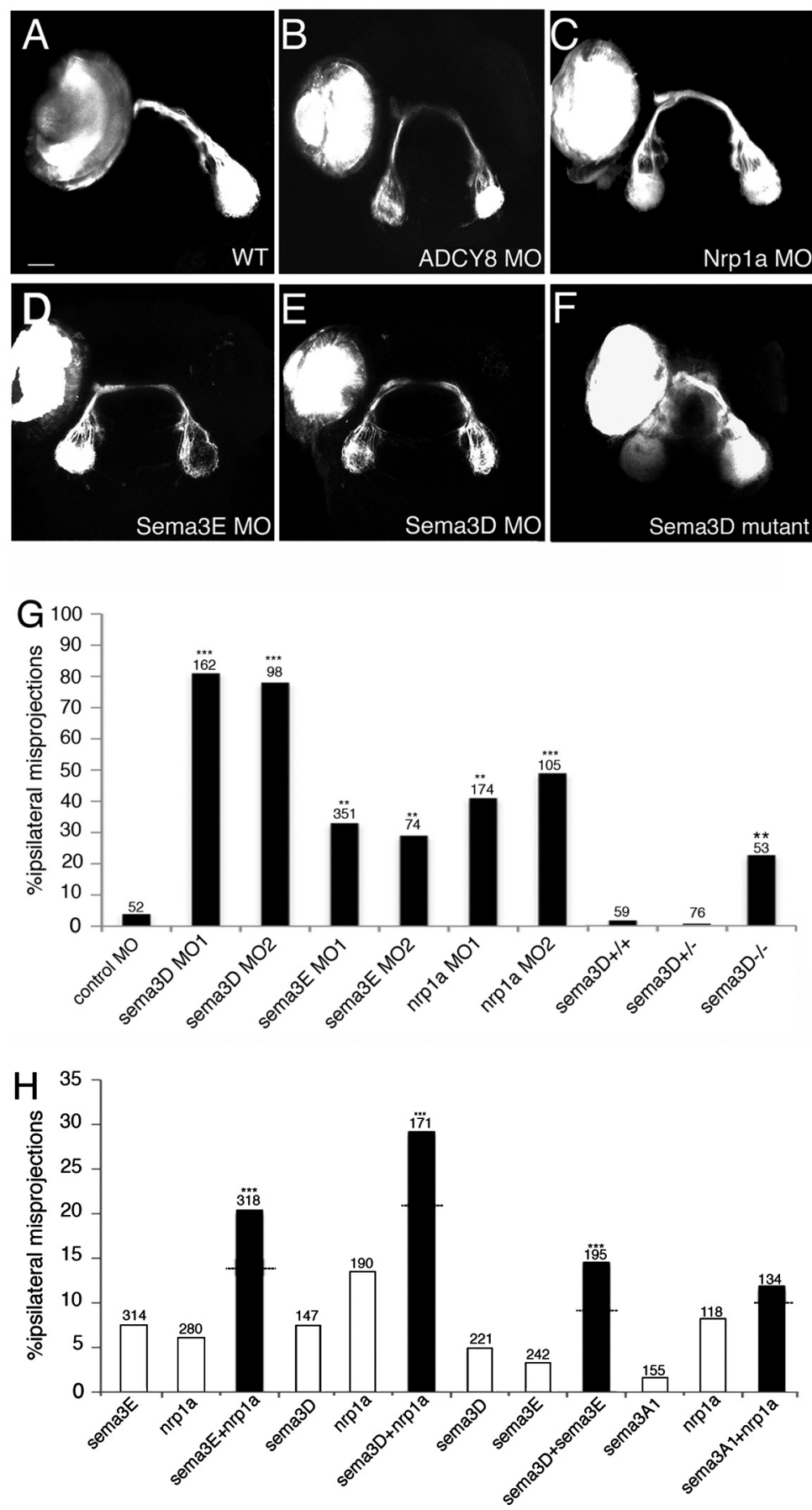

Figure 2. Expression of $\mathrm{DNG} \alpha_{\mathrm{S}}$ in $\mathrm{RGCS}$ phenocopies knockdown of adcy 8 or semaphorin signaling components. $A$, All retinal axons cross the midline and project to the contralateral tectum in $5 \mathrm{dpf}$ WT embryos. $\boldsymbol{B}-\boldsymbol{F}$, Ipsilateral misprojections are observed in adcy8 morphant $(\boldsymbol{B})$, nrp1a morphant $(\boldsymbol{C})$, sema3E morphant $(\boldsymbol{D})$, sema3D morphant $(\boldsymbol{E})$, and sema3D mutant $(\boldsymbol{F})$ embryos. $\mathbf{G}$, The percentage of eyes with ipsilateral misprojections are observed using either of two independent MOs for sema3D, sema3E, nrp1a, and sema3D mutant embryos. ${ }^{* *} p<0.001,{ }^{* * *} p<0.0001$ using the Fisher's exact test. Sema and nrp 1 morphant embryos were compared with embryos injected with control M0. Sema3D mutants were compared with WT sibling controls. $\boldsymbol{H}$, Coinjection of low doses of pairs of MOs targeting nrp1a, sema3d, or sema3E produce synergistic increases in ipsilateral misprojections. The proportions of ipsilateral retinal misprojections induced by knocking down each combination of class 3 semaphorin and/or $n r p 1 a$ are indicated. The white bars show responses to low doses of $M 0$ targeting class 3 semaphorins and/or nrp1a, respectively. The black bars indicate the response to a combination of the same low doses of MOs. The number of eyes examined in each condition is indicated above each column. Stars above the columns indicate that the percentage of eyes with ipsilateral retinal misprojections induced by the combination of half doses is significantly higher than would be expected by assuming that the effects of small doses add together independently ${ }^{* * *} p<0.00001$ using a Monte Carlo-based analysis that estimates the probability that observed phenotypes are independent and additive. Scale bar, $50 \mu \mathrm{m}$. 
targeting sema3A1 do not synergize with MOs to nrpla. We conclude that cAMP produced by $\mathrm{G} \alpha_{\mathrm{S}}$ and/or ADCY8, Sema3D, Sema3E, and Nrpla, are all required for normal midline crossing.

\section{Retinal axons of sema3D mutant embryos misproject to the} ipsilateral tectum

We also examined the sema3 $D^{\text {sal661 }}$ mutant line that contains a premature stop codon in the sema domain. Ipsilateral retinal misprojections were observed in $23 \%$ of the eyes examined, confirming results obtained in the sema3D morphant embryos (Fig. $2 F, G)$. These embryos display ipsilateral retinal misprojections at a lower penetrance than sema3D morphants. One possible explanation is that general toxicity or off-target effects of the MOs sensitize the fish for sema3D-specific knockdown. Consistent with this idea, we observe occasional $(\sim 4 \%)$ ipsilateral misprojections in embryos injected with a random control MO. Another possibility is that there is a maternal contribution of sema3D mRNA that is knocked down by the MOs we used. We also examined the $n r p 1 a^{s a 1485}$ mutant line in which a premature stop codon is expected to truncate Nrpla before its transmembrane domain. Abnormal ipsilateral retinal misprojections were not detected in these mutant embryos. Thinking that maternally expressed nrpla might be affecting the outcome, embryos produced from the mating of two homozygous $n r p 1 a^{\text {sal485 }}$ fish were examined. High lethality $(>50 \%)$ was observed in these clutches. A few sparse ipsilateral misprojections were observed in $12 \%$ of the survivors $(n=58)$. Surprisingly, defects in motor neuron pathfinding reported previously in $n r p 1 a$ morphants and in plexinA3 mutants were not observed in these embryos, raising the possibility that $n r p 1 a^{s a 1485}$ is hypomorphic (Feldner et al., 2005, 2007; Palaisa and Granato, 2007). The lack of an ipsilateral misprojection phenotype in $n r p 1 a^{\text {sal }}{ }^{485}$ mutant embryos might be explained in several ways. Functional transcripts are produced from a putative null allele of foxd 3 in which a premature stop codon is occasionally skipped during transcription (Chang and Kessler, 2010; D. Kessler, personal communication). Alternatively, embryos harboring $n r p 1 a^{\text {sal485 }}$ may compensate for the loss of nrp 1 a more effectively than nrp 1 a morphants, for example, by the upregulation of one or more of the other three neuropilins. $n r p 1 b$ is normally expressed in RGCs and is an attractive candidate for compensation (Fig. 3E). We attempted knockdown experiments with $n r p 1 b$ MOs, but high lethality at early ages made it impossible for us to analyze the retinal projections of these animals. We think it unlikely that ipsilateral retinal misprojections in nrpla morphant embryos can be ascribed to purely off-target effects because these errors are rescued by the reexpression of nrpla specifically in RGCs (Fig. 4).

\section{sema3D and sema3E are expressed near the chiasm as RGC axons cross the midline}

After exiting the eye at $\sim 32 \mathrm{hpf}$, the first retinal axons extend across the ventral midline to form the chiasm between 34 and 36 hpf (Poulain et al., 2010). We performed in situ hybridization on 36 hpf embryos to determine whether sema3D or sema3E are expressed along the optic tract as retinal axons navigate through the ventral midline. sema $3 D$ is expressed at the midline both dorsal and ventral to the chiasm (Fig. $3 A, C$ ). sema $3 E$ is expressed more broadly just ventral to the chiasm (Fig. $3 B, C$ ). Retinal axons traverse the chiasm immediately adjacent to ventrally expressed sema3D and sema3E but do not extend axons within the expressing tissues. Within the retina, low levels of nrp $1 a$ and $n r p 1 b$, coreceptors for class 3 Semaphorins and VEGF, are expressed in 36 hpf RGCs (Fig. 3D,E). The expression of nrpla in
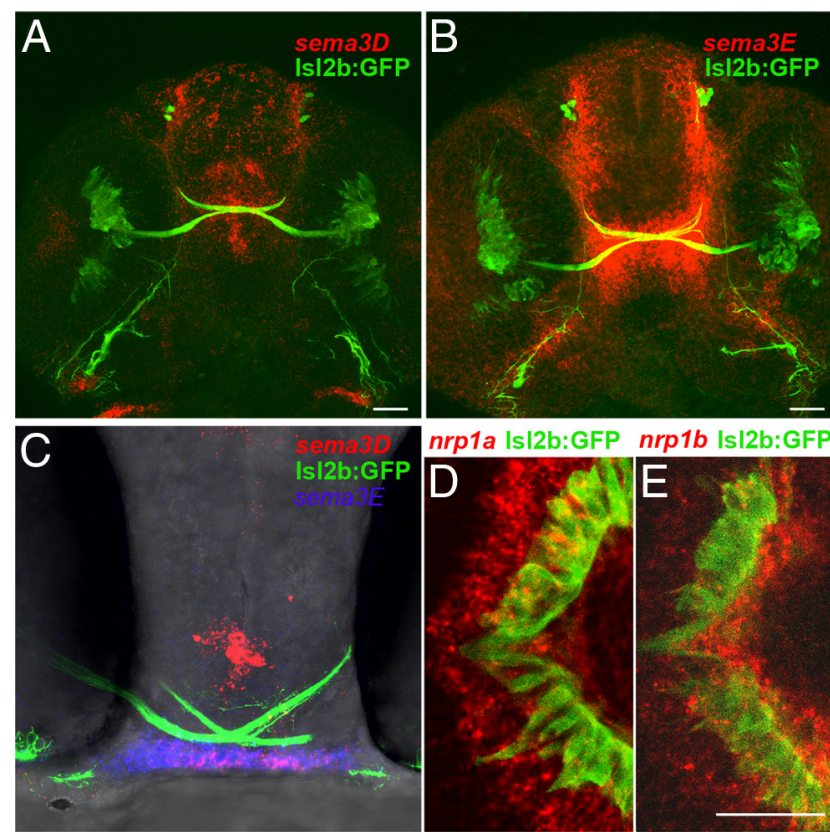

Drp

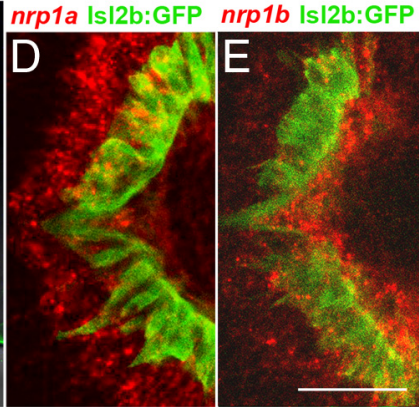

Figure 3. sema3D and sema3E are expressed near the chiasm, and nrp $1 a$ and nrp $1 b$ are expressed in RGCs. A subset of RGCs and their axonal projections were visualized with $/ s / 2 b$ :GFP transgene expression, and the expression patterns of semaphorin signaling components were detected by in situ hybridization with the indicated RNA probes. $\boldsymbol{A}, \boldsymbol{B}$, Ventral views of $36 \mathrm{hpf}$ embryos showing that sema3D $(\boldsymbol{A})$ and $\operatorname{sema} 3 E(\boldsymbol{B})$ are expressed in the vicinity of the optic chiasm. C, A frontal view demonstrates that sema3D (red) is expressed both dorsal and ventral to crossing retinal axons (green), whereas sema3E (blue) is expressed ventral to the chiasm. $\boldsymbol{D}$, $\boldsymbol{E}, n r p 1 a$ (red) and nrp $1 b$ (red) are expressed in RGCs (green) at $36 \mathrm{hpf}$. Scale bars, $50 \mu \mathrm{m}$.

RGCs is consistent with previous studies that reported nrpla, $n r p 1 b, n r p 2 a$, and $n r p 2 b$ expression in RGCs (Bovenkamp et al., 2004; Liu et al., 2004; Yu et al., 2004). These results demonstrate that sema3D and sema3E are expressed at the appropriate time and place to help guide retinal axons across the ventral midline.

Ipsilateral misprojections of retinal axons in nrpla morphant embryos can be corrected by re-expression of nrp1a in RGCs Morpholino knockdowns have the potential for off-target or nonspecific toxic effects that can cloud their interpretation. Therefore, we used a rescue-based approach to determine whether nrpla is required cell autonomously in RGCs for normal retinal pathfinding. Single eyes in nrpla morphant embryos were electroporated at $24 \mathrm{hpf}$, well before retinal axons cross the midline, with plasmids encoding either HuC:Gal4 or Ath7:Gal4 to drive UAS expression selectively in RGCs and either a UAS:citrine (control) construct or a UAS:nrp1a;UAS:citrine (rescue) construct (Fig. $4 A, B$ ). The axon trajectories of citrine-labeled RGCs were traced at $4 \mathrm{dpf}$ (Fig. $4 C$ ). A majority of morphant embryos that expressed the control construct were observed to contain ipsilateral retinal misprojections (Fig. 4D,F). The frequency of ipsilateral misprojections was significantly reduced in morphants expressing the nrpla rescue construct (Fig. 4E,F). We conclude that nrpla is required within RGCs to facilitate retinal axon crossing at the ventral midline.

\section{Multiple Plexins may contribute to retinal midline crossing.}

Neuropilin is only one component of the class 3 Semaphorin complex that includes Plexins and Ig superfamily members such as L1 or NrCAM (for review, see Pasterkamp, 2012; Sharma et al., 2012). One key question is which Plexins are expressed in RGCs and transduce Sema3D and 3E signals at the midline. We exam- 
A

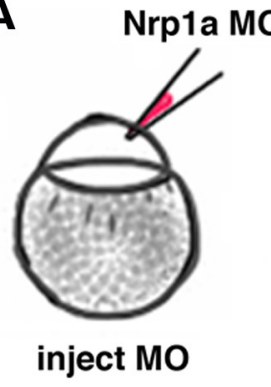

$1 \mathrm{hpf}$

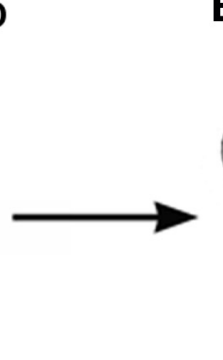

B

\section{ectroporate citrine control or Nrp1a rescue construct}

24hpf

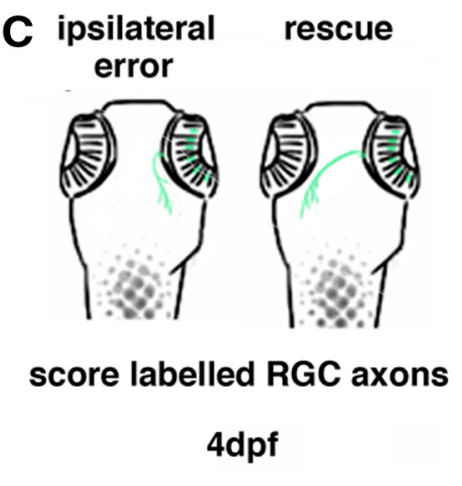

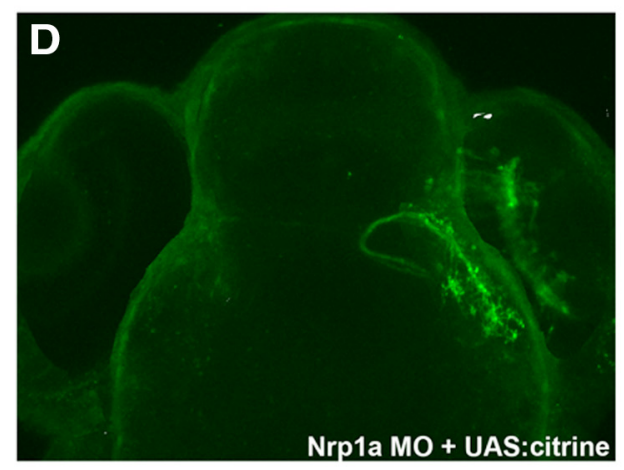
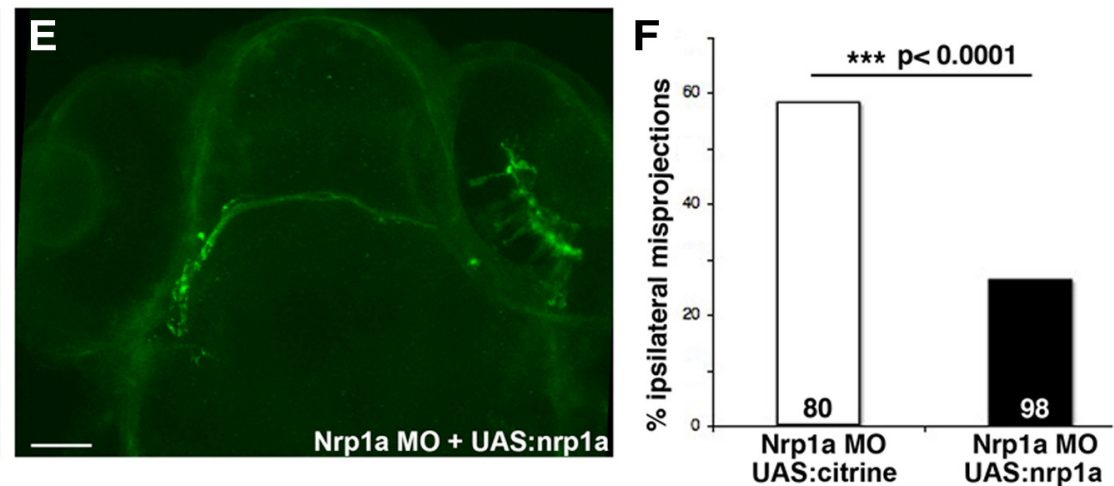

Figure 4. The expression of nrp1a in RGCs rescues ipsilateral misprojections in nrp1a morphants. $\boldsymbol{A}, \boldsymbol{B}$, One-cell stage embryos were injected with nrp1a MO (A) and allowed to develop to 24 hpf when plasmids containing Ath7:Gal4 and either UAS:citrine (control condition) or UAS:nrp 1a:UAS:citrine (rescue condition) were electroporated into one eye (B). C, Citrine-labeled retinal projections were visualized at $4 \mathrm{dpf} . \boldsymbol{D}, \boldsymbol{E}$, Representative images of electroporated embryos. Background staining unrelated to the retinal projections was removed before making these maximum projection images (see Materials and Methods). $\boldsymbol{D}$, an example of ipsilateral misprojecting retinal axons in an nrp1a morphant expressing the control construct (arrowhead). $\boldsymbol{E}$, An example of correctly routed retinal projections in a nrp 1a morphant in which a nrp 1a rescue construct is expressed in the labeled RGCS. $\boldsymbol{F}$, Quantification of results represented in $\boldsymbol{D}$ and $\boldsymbol{E}$. Expression of $n r p 1 a$ in RGCs significantly reduced the percentage of electroporated eyes containing labeled ipsilateral misprojections in nrp1a morphant embryos. The number of zebrafish larvae in each condition are indicated in the columns. $p<0.0001$ by Fisher's exact test. Scale bar, $50 \mu \mathrm{m}$.

ined the expression patterns of zebrafish plexinAla, plexinAlb, plexinA2, plexinA3, plexinA4, plexinB1a, plexinB1b, plexinB2, and plexinD1. We detected expression of all but plexinA4 and plexinB1a in the RGC layer at $36 \mathrm{hpf}$ (consistent with Christie et al., 2006). Thus, expression analysis of the vertebrate plexins did not reveal an obvious single candidate for a role in Sema3D/3Emediated RGC guidance. We also analyzed the retinotectal projections in plexinA3 (sidetracked) mutants (Palaisa and Granato, 2007). No ipsilateral misprojections were evident in 26 projections analyzed. Tectal borders seemed to be shifted toward the midline in these mutants, suggesting that plexin $A 3$ may mediate later stages of RGC guidance, tectum formation, or the overall morphology of midline structures. We also performed knockdown experiments targeting plexinA1 with two different MOs. We observed a very few minor ipsilateral misprojections in 8 of 110 eyes when using a translation-blocking $\mathrm{MO}$ and in 3 of 40 eyes using high doses of splice-blocking MO. PlexinAl might therefore contribute to retinal responses to semaphorins at the midline but cannot account for the scope of errors observed in Sema3D, Sema3E, Nrpla, or ADCY8/DNG $\alpha_{\mathrm{S}}$ loss-of-function experiments. In the mouse, Sema3E acts as a repellent for corticospinal axons when signaling through PlexinD1 but an attractant for subiculo-mammilary neurons when signaling via PlexinD1 and Nrp1 (Chauvet et al., 2007). PlexinD1 mutants are available in the zebrafish (Torres-Vázquez et al., 2004). plexinD1 is expressed in RGCs at $36 \mathrm{hpf}$, but analysis of plexinD1 mutants did not reveal any ipsilateral misprojections in 22 projections examined. Based on these findings, we surmise that multiple Plexins are likely to contribute to Sema3D/Sema3E-mediated axon guidance in navigating zebrafish RGCs, consistent with previous reports that Plexins can act redundantly (Schwarz et al., 2008).

Interactions between cAMP and Nrp1a-mediated signaling pathways

Either the expression of a DNG $\alpha_{S}$ in RGCs or the knockdown of calcium/calmodulin-stimulated ADCYs induce ipsilateral misprojections of retinal axons. These results suggest that lowered cAMP levels lead to aberrant retinal pathfinding. If this is the case, interfering with $G \alpha_{S}$ and calmodulin-mediated pathways at the same time should have a synergistic effect in producing retinal pathfinding errors. Generally consistent with this expectation, low doses of an adcy $8 \mathrm{MO}$ injected into embryos with a single copy of the $\mathrm{DNG} \alpha_{\mathrm{S}}$ transgene induces a higher, although not quite statistically significant, frequency of embryos with ipsilateral retinal misprojections than would be expected by simply summing together the effects of the $\mathrm{DNG} \alpha_{\mathrm{S}}$ and the adcy $8 \mathrm{MO}$ (Fig. $5 \mathrm{~A}$ ). This result raises the possibility that the $\mathrm{G} \alpha_{\mathrm{S}}$ and $A D C Y 8$ signaling pathways converge together at the level of cAMP production.

Because interfering with the activation of ADCYs phenocopies the knockdown of semaphorin signaling components, we hypothesized that cAMP levels regulate semaphorin signaling in retinal axons. To further explore interactions between signaling elements in the cAMP pathway and the semaphorin signaling pathway, we tested whether knockdowns in these two pathways synergize. Low doses of a nrpla MO injected 

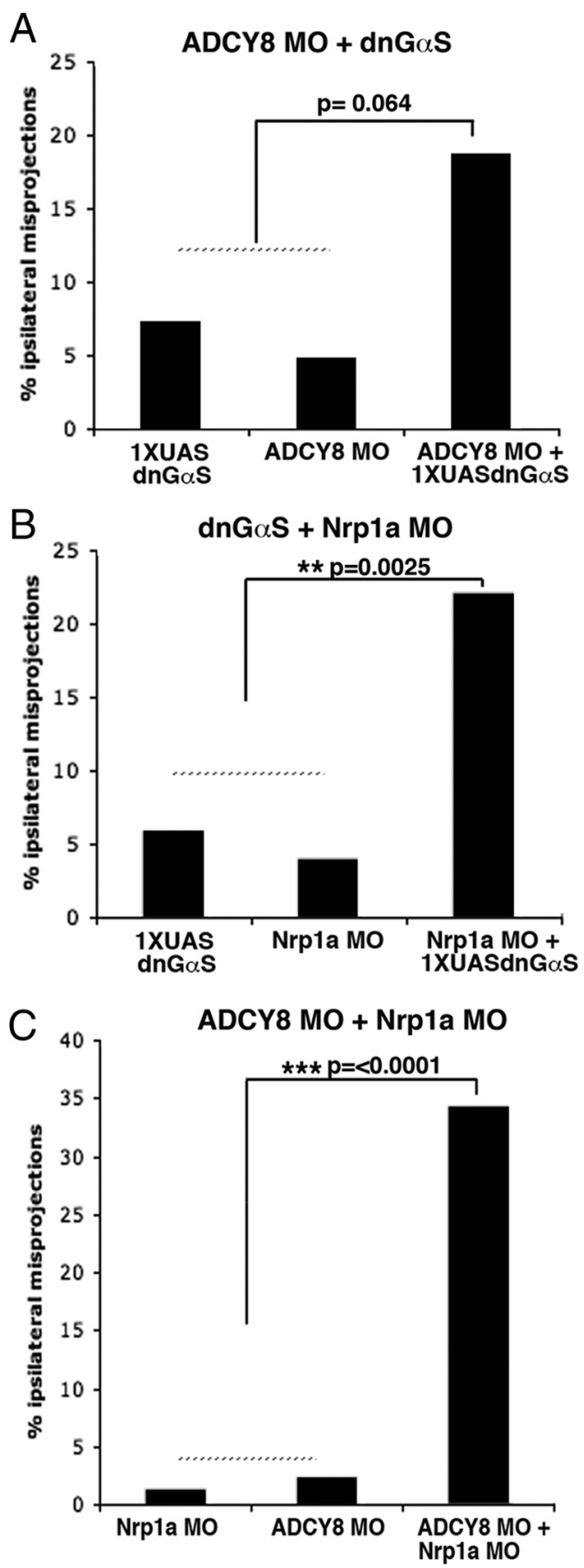

Figure 5. Synergistic interactions between CAMP and Nrp1a-mediated signaling pathways. $\boldsymbol{A}-\boldsymbol{C}$, Quantification of ipsilateral misprojections detected by Dil or DiD labeling at $5 \mathrm{dpf}$. , Embryos containing one copy of the UAS:DNG $\alpha_{5}$ and injected with a low dose of adcy $8 \mathrm{M} 0$ have a higher percentage of eyes with ipsilateral misprojections than expected if the effects of each perturbation are independent and sum linearly. $\boldsymbol{B}$, Similarly, a single copy of UAS:DNG $\alpha_{5}$ and a low dose of nrp1a $\mathrm{M0}$ act synergistically to induce ipsilateral misprojections. C, Coinjection of low doses of nrp1a and adcy8 MOs synergize to produce ipsilateral misprojections. In each panel, the dotted line represents the incidence of misprojections expected if the two conditions sum linearly. $p$ values indicate the probability that the combined effect effects are independent and additive.

into embryos with a single copy of the DNG $\alpha_{\mathrm{S}}$ transgene induce a significantly higher frequency of embryos with ipsilateral retinal misprojections than would be expected by summing together the effects of either manipulation alone (Fig. 5B). Even stronger synergistic effects were seen when embryos were injected with nrp1a and adcy 8 MOs (Fig. 5C).
We conclude that cAMP and Semaphorin/Neuropilin signaling pathways interact to facilitate retinal midline crossing.

$n r p 1 a$ transcript levels are decreased in DNG $\alpha_{\mathrm{S}}$ transgenics and in adcy 8 morphants

This interaction between the two signaling pathways led us to hypothesize that CAMP-mediated signaling promotes the expression of nrp1 in RGCs. Imai et al. (2006) have proposed that a $\mathrm{G} \alpha_{\mathrm{S}}$-mediated cAMP-, PKA-, and CREB-dependent pathway promotes the expression of $n r p 1$ in olfactory sensory neurons and thereby helps target their axons along the anteroposterior axis of the mouse olfactory bulb (Imai et al., 2006). ADCY3 is a critical mediator of cAMP signaling downstream of olfactory receptors. ADCY3 knock-out mice are anosmic and display disorganized and mistargeted axonal projections (Wong et al., 2000; Chesler et al., 2007). In vascular progenitors, Nrp1 is upregulated by cAMP through a PKA-dependent mechanism (Yamamizu et al., 2009). Based on these findings and our interaction data, we hypothesized that decreased cAMP levels in DNG $\alpha_{\mathrm{S}}$ transgenic or adcy8 morphant embryos might result in decreased expression of nrpla. We used qPCR to examine nrpl expression levels in control embryos compared with $\mathrm{DNG} \alpha_{\mathrm{S}}$-expressing or adcy 8 morphant embryos. Because both $\mathrm{G} \alpha_{\mathrm{S}}, n r p 1 a$, and $n r p 1 b$ are broadly expressed in the nervous system, the s1101t:Gal4 line was used to drive $\mathrm{DNG} \alpha_{\mathrm{S}}$ expression pan-neuronally in embryos harboring up to three copies of the UAS:DNG $\alpha_{\mathrm{S}}$ transgene (Li et al., 2000; Yu et al., 2004; Scott and Baier, 2009; Oka and Korsching, 2011). qPCR was performed to measure either $n r p 1 a$ or $n r p 1 b$ expression levels in embryos containing no copies, one to two copies, or one to three copies of the DNG $\alpha_{\mathrm{S}}$ transgene (Fig. $6 A, B$ ). Expression of the highest number of copies of $\mathrm{DNG} \alpha_{\mathrm{S}}$ suppresses $n r p 1 a$ expression to $42 \%$ of control levels and $n r p 1 b$ expression to $4 \%$ of control levels. Similar qPCR experiments were repeated to measure nrpla expression in pools of embryos in which we determined the precise number of copies of $\mathrm{DNG} \alpha_{\mathrm{S}}$. First, we performed qPCR on genomic DNA from tails of fluorescent embryos to determine the number of $\mathrm{DNG} \alpha_{\mathrm{S}}$ copies for each individual embryo. The heads of these animals were then pooled according to copy number. nrpla expression levels were determined for each pool and normalized to levels of nonfluorescent siblings. Pools containing one copy of UAS:DNG $\alpha_{\mathrm{S}}$ express $80 \%$ measured nrpla mRNA compared with sibling controls. Embryos expressing two copies of UAS:DNG $\alpha_{\mathrm{S}}$ have $31 \%$ of control nrpla levels (Fig. 6C). There is no significant change in another cell surface receptor, $c x c r 4$, in either $\mathrm{DNG} \alpha_{\mathrm{S}}$-expressing or adcy 8 morphant embryos (Fig. 6C,D). nrpla expression is reduced to $59 \%$, and $n r p 1 b$ is reduced to $57 \%$ of control levels in WT embryos injected with adcy 8 MOs compared with uninjected agematched controls (Fig. 6E, F). These results show that interfering with the production of cAMP through either $\mathrm{G} \alpha_{\mathrm{S}^{-}}$or ADCY8mediated pathways reduces $n r p 1 a$ and $n r p 1 b$ expression, consistent with the hypothesis that cAMP signaling affects retinal axon midline crossing through the regulation of nrp1 expression.

Expressing nrpla in RGCs rescues retinal misprojections in adcy 8 morphants

We hypothesized that reduced cAMP causes a reduction in $n r p 1 a$ levels in RGCs and that, as a consequence, retinal axons misproject ipsilaterally because they cannot respond appropriately to sema3D, sema3E, or other ligands at the ventral midline. If true, then re-expressing $n r p 1 a$ within RGCs in cAMP-deficient adcy8 morphant embryos should re-establish normal crossing of retinal axons. Control or adcy8 morphant embryos containing the Ath7: 
Gal4 transgene and either the UAS:citrine (control) or UAS:nrp1a;UAS:citrine (rescue) transgenes were allowed to develop to $3 \mathrm{dpf}$ (Fig. 7A). One eye was removed, and the larvae were allowed to develop to $5 \mathrm{dpf}$ (Fig. $7 \mathrm{~B}, \mathrm{C}$ ). The optic nerve and tract from the damaged eye degenerates during the $2 \mathrm{~d}$ period after eye removal, and the projection from the remaining eye is visualized by the expression of Gap43citrine (Fig. 7D). In non-morphant embryos expressing a control construct, a small proportion of embryos have barely discernable ipsilateral projections. These may represent axons that have not completely degenerated, misrouted newly extended retinal axons from the remaining eye, or sprouting from the intact retinal tract. Previous studies in Xenopus detected aberrant ipsilateral connections between the intact eye and the ipsilateral tectum after relatively long survival times when one eye was removed (Fraser and Hunt, 1980). Approximately the same proportion of embryos in all conditions displayed these very weak ipsilateral projections. Consistent with our previous observations, retinal axons in nearly half of adcy 8 morphant embryos had strong ipsilateral misprojections (Fig. 7E,F). Expression of the nrpla rescue construct in adcy 8 morphants reduced strong misprojections to control levels (Fig. $7 F$ ). Overexpression of nrpla in non-morphant embryos did not have any observable effect. We conclude that ipsilateral pathfinding errors observed in adcy 8 morphants can be explained by reduced nrp1 expression levels.
A

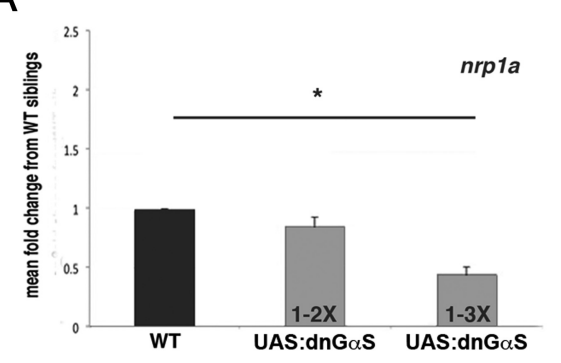

C

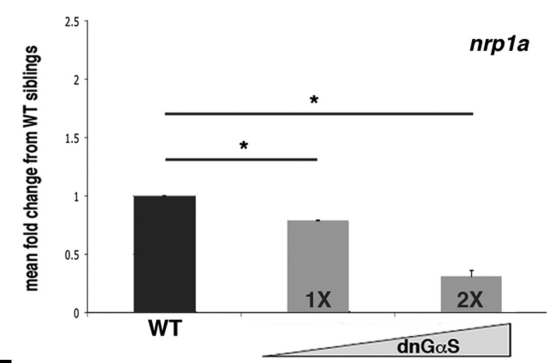

$E$

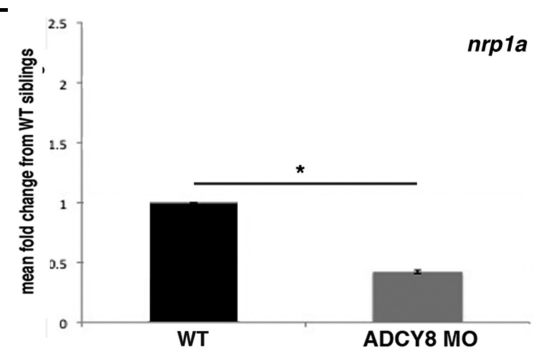

B

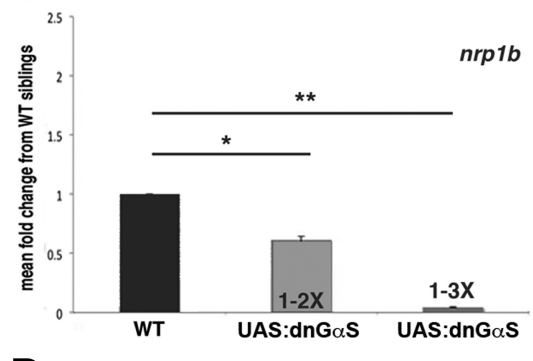

D
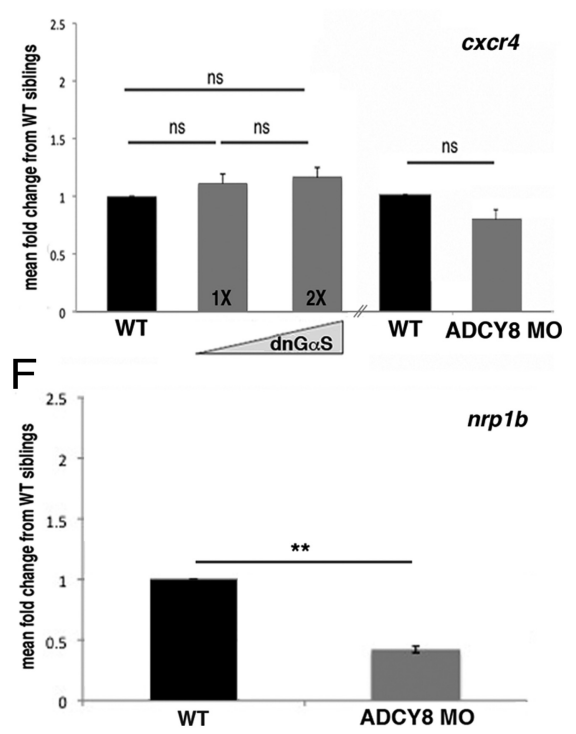

Figure 6. Nrp1 transcript levels are decreased in DNG $\alpha_{\varsigma}$ transgenic and adcy8 morphant embryos. Because DNG $\alpha_{\varsigma}$ expression is increased, nrp $1 a$ and nrp $1 b$ expression is reduced. $\boldsymbol{A}, \boldsymbol{B}$, Progeny of transgenics containing multiple copies DNG $\alpha_{5}$ were pooled according to parental copy number. DNG $\alpha_{\varsigma}$ transgene expression was driven by the pan-neuronal driver s1101t:Gal4. cDNA was generated from pooled nonfluorescent siblings to serve as controls. Both $n r p 1 a$ and $n r p 1 b$ transcripts are significantly reduced in pools from parents with either two or three copies of the DNG $\alpha_{\mathrm{S}}$ transgene. $C, q P C R$ was performed to measure nrp 1a expression in cDNA prepared from pools of $48 \mathrm{hpf}$ heads containing exactly one or two copies of the DNG $\alpha_{\mathrm{s}}$ transgene. Nrp1a expression is significantly reduced in embryos with one copy of the $\mathrm{DNG} \alpha_{\mathrm{s}}$ transgene and more greatly reduced in embryos with two copies. $D$, Expression of $c x c r 4$ was not affected by either DNG $\alpha_{\mathrm{S}}$ expression or adcy8 knockdown. $\boldsymbol{E}, \boldsymbol{F}$, Expression level of $n r p 1 a$ and $n r p 1 b$ were reduced in adcy 8 morphant embryos. ${ }^{*} p<0.05,{ }^{* *} p<0.01$ using Student's $t$ test.

\section{Discussion}

We undertook this study to explore the possibility that GPCRmediated signaling helps guide axons in the developing nervous system. We showed previously that activation of the GPCRs CXCR4 or mGluR1 reduce axonal responses to repellent cues through a $\mathrm{G} \alpha_{\mathrm{i}^{-}}, \mathrm{G} \alpha_{\mathrm{q}^{-}}, \mathrm{G} \beta \gamma^{-}$, and cAMP-mediated signaling pathway (Twery and Raper, 2011). This effect is rapid, occurring over a timescale of minutes, and is therefore likely to involve a signaling process that is localized to the growth cone. In contrast, in this study, we find that a presumed elevation of cAMP mediated through $\mathrm{G} \alpha_{\mathrm{S}}$ and/or ADCY8 induces elevated mRNA levels for a key axonal guidance receptor component, Nrp1. This represents a countervailing and possibly longer-acting influence on guidance receptor activity that is complementary to our previous findings. Our results underscore the potential for local cAMPproducing signaling events induced, for example, by GPCR activation, to determine the outcomes of subsequent guidance decisions by regulating guidance receptor expression.

The regulation of guidance receptor expression or availability influences axon guidance in a wide variety of systems (Huber et al., 2003; O'Donnell et al., 2009). For example, ERB/Neuregulin1 signaling regulates surface levels of $\mathrm{Nrp} 1$ in DRG axons through an unknown mechanism (Hancock et al., 2011). Consequently, the axon trajectories of TrkA-expressing DRG sensory axons in the spinal cord of Neuregulin1 mutants resemble those of Sema3A null animals. The semaphorin receptor PlexinA1 is upregulated in spinal commissural neurons on contact with the floor plate, making their axons responsive to Sema3B expressed at the midline and thereby promoting a repellent interaction that drives them contralaterally (Zou et al., 2000; Nawabi et al., 2010). Recent work suggests that local GDNF signaling from the floor plate increases PlexinA1 on commissural axon growth cones by inhibiting calpain-mediated degradation of the receptor (Charoy et al., 2012). Similarly, Xenopus RGCs are repelled by Sema3A only after crossing the midline (Campbell et al., 2001). Cyclic nucleotide levels can control the surface levels of key guidance receptors. The sensitivity of pre-crossing commissural axons to netrin is enhanced by an ADCY and cAMP-dependent PKA activity that promotes insertion of DCC (deleted in colorectal cancer) into the cell membrane (Bouchard et al., 2004; Moore and Kennedy, 2006). Work from the Sakano laboratory has shown that cAMP-modulated Nrpla expression affects axonal fasciculation and glomerulus formation in the primary olfactory projection (Imai et al., 2006). Here we show that cAMP-mediated Nrp1 expression facilitates retinal axon navigation through an inter- 
A

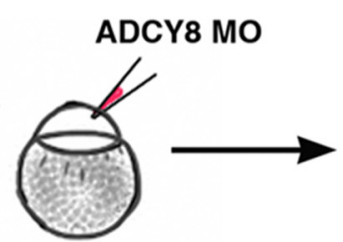

Ath7:Gal4;UAS:nrp1a (rescue)
or
B

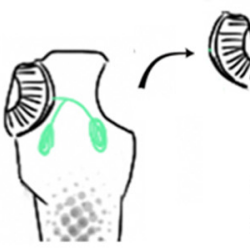

Remove one eye control control Nrp1a

ADCY8MO ADCY8MO

ipsi

rescue?

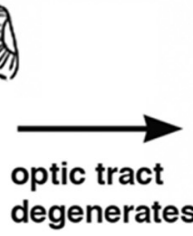

C
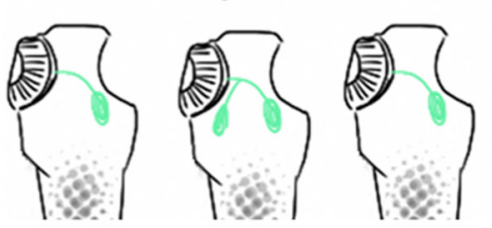

Score tectal projections

Ath7:Gal4;UAS:citrine (control)

1hpf

$3 \mathrm{dpf}$

$5 \mathrm{dpf}$

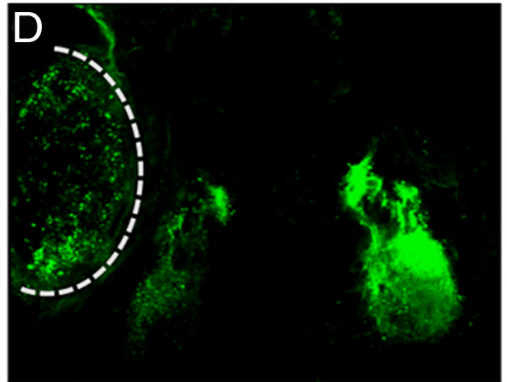

ADCY8 MO + UAS:citrine

strong ipsilateral

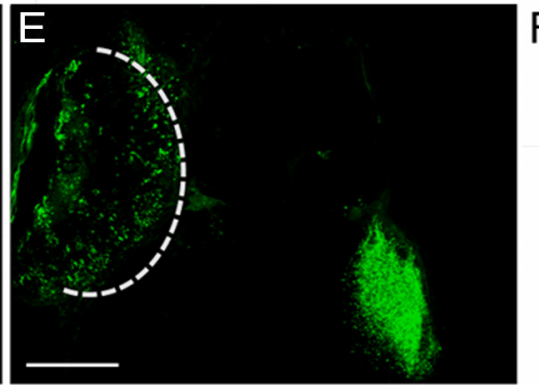

ADCY8 MO + UAS:nrp1a contralateral

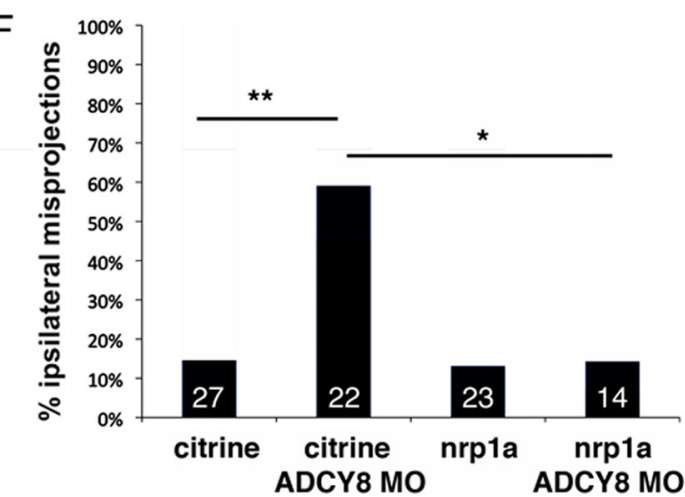

Figure 7. Retinal misprojections in adcy 8 morphants are rescued by expressing nrp 1a in RGCs. $A$, adcy8 morphant or non-morphant embryos were produced from just-fertilized eggs containing either the Ath7:Gal4;UAS:citrine (control) or the Ath7:Gal4;UAS:nrp1a:UAS:citrine (rescue) transgenes. $\boldsymbol{B}$, One eye was removed from each fluorescent embry0 at 3 dpf. The optic tract from the removed eye degenerates over the next $2 \mathrm{~d}$. C, Embryos were analyzed for ipsilateral misprojections at $5 \mathrm{dpf}$. D, Representative image in an adcy 8 morphant embryo in which RGCs expressing the control construct are visualized by their expression of citrine. Retinal axons project to both the contralateral and ipsilateral tecta. $\boldsymbol{E}$, Representative image of a contralateral projection in an adcy 8 morphant embryo in which RGCs express the UAS:nrp1a rescue construct. $F$, A comparison of the percentage of eyes with labeled ipsilateral misprojections in embryos expressing either the control construct or the nrp1a rescue construct in adcy 8 morphant embryos. Expression of the rescue construct in RGCs corrects ipsilateral misprojections. Expression of the rescue construct in non-morphant embryos had no observable affect. ${ }^{*} p<0.05,{ }^{* *} p<0.01$ by Fisher's exact test. Scale bar, $100 \mu \mathrm{m}$.

mediate target, the optic chiasm, in which repulsive, attractive, and modulatory cues must all be appropriately integrated.

We do not know the mechanism by which cAMP induces elevated nrp1a levels in RGCs. Either the transcription or the stability of nrpla mRNA could be affected. One appealing hypothesis is that cAMP signaling induces nrpla transcription through its canonical effector, the basic leucine zipper domain (bZIP) transcription factor CREB. GPCR activation can lead to elevated cAMP, the phosphorylation of PKA, and the resulting activation of CREB (Lonze and Ginty, 2002; Carlezon et al., 2005). In mouse, Nrp1 expression increases in olfactory sensory neurons expressing $\mathrm{caG} \alpha_{\mathrm{S}}$, PKA, or CREB; suggesting that cAMP acts via CREB to promote Nrp1 expression (Imai et al., 2006). CREB knock-out mice display axon guidance errors independent of neurotrophin-dependent survival defects (Lonze et al., 2002). A canonical activator of CREB, NGF, maintains nrp1 expression in sensory axons (Pond et al., 2002). Similar but not identical axon guidance and branching errors are observed in mouse CREB compared with $N r p 1^{\text {sema-l- }}$ mutants, perhaps because CREB affects additional signaling pathways besides those that are Nrp1 dependent (Rudolph et al., 1998; Lonze et al., 2002; Gu et al., 2003). There are multiple consensus binding sites for CREB within the $5 \mathrm{~kb}$ of sequence upstream of zebrafish nrpla and $n r p 1 b$. This is consistent with the idea that CREB could mediate cAMP-dependent nrp $1 a$ and $n r p 1 b$ expression. Alternatively, direct upregulation of transcription could occur via another
cAMP-dependent bZIP transcription factor, such as CREM (cAMP response element modulator) or ATF (activating transcription factor), or through a PKA-independent mediator, such as EPAC (exchange proteins activated by cAMP) (Sands and Palmer, 2008).

Our results suggest that GPCR activation induces sufficient Nrp1 expression for normal retinal axon pathfinding. A major outstanding question is which $\mathrm{G} \alpha_{\mathrm{S}}$-coupled GPCRs are responsible for maintaining cAMP levels in RGCs. The $\mathrm{G} \alpha_{\mathrm{S}}$-coupled A2b receptor maintains cAMP levels in young Xenopus RGCs and thereby promotes their attraction to netrin at the optic nerve head (Shewan et al., 2002). A2b is also expressed in zebrafish retinae (Boehmler et al., 2009). $\mathrm{D}_{1}$-type dopamine receptors, which canonically induce cAMP production, have been shown to affect neurite outgrowth in chick retinal explants and are expressed in zebrafish RGCs (Lankford et al., 1988; Mora-Ferrer et al., 1999). GPCRs may elevate cAMP levels through alternate pathways (Daaka et al., 1997; Selkirk et al., 2001). Cxcr4 is expressed in RGCs, and its activation has been proposed to elevate cAMP levels (Xu et al., 2010). Cxcr4 is required for retinal axons to project normally out of the eye, and its activation can affect retinal axon responses to the midline retinal repellent Slit2 ( $\mathrm{Li}$ et al., 2005; Chalasani et al., 2007). Sonic hedgehog (Shh) signals via the seven transmembrane GPCR Smoothened, which is expressed in RGCs. Its loss induces RGC misprojections in mouse, Xenopus, and zebrafish (Barresi et al., 2005; Sánchez-Camacho 
and Bovolenta, 2008; Gordon et al., 2010). Some or all of these misprojections can be attributed to the important role Shh plays in the specification of midline structures (Barresi et al., 2005). We previously showed that mGluRs can modulate axonal responses to repellents, presumably through an elevation of cAMP. Zebrafish homologs of mGlur1, mGlur5, and mGlur6 are all expressed in the retina (data not shown). Potentially, any or all of these and other GPCRs expressed in RGCs could help regulate cAMP levels, consistent with normal retinal axon crossing at the ventral midline.

Sema3D has been reported to promote retinal axon crossing at the optic chiasm (Sakai and Halloran, 2006). We demonstrate that Sema3D and Sema3E are both expressed immediately adjacent to the zebrafish optic chiasm and that they facilitate retinal axon crossing. Our findings are consistent with the idea that they do so through their interaction with Nrp1 expressed in RGCs. The simplest explanation for our results is that Sema3D and Sema3E act as permissive factors or attractants that facilitate retinal axon growth across the midline. At the mouse optic chiasm, Sema6D, PlexinA1, and NrCAM are all expressed on midline glial cells and together facilitate the crossing of RGC axons (Kuwajima et al., 2012). In Nrp1 mutant mice, retinal axons misproject ipsilaterally, although in this instance the ligand of neuropilin is VEGF rather than a semaphorin (Erskine et al., 2011). Our results are consistent with Sema3D and Sema3E promoting retinal axon outgrowth. We cannot rule out the possibility that VEGF further contributes to retinal midline crossing in our system. Sema3D and Sema3E can act as either repellents or attractants depending on the receptor components expressed in responding axons (Wolman et al., 2004; Chauvet et al., 2007). Sema3D is reported to promote the crossing of axons in the anterior commissure but to repel ventral RGC axons in the zebrafish tectum (Liu et al., 2004; Wolman et al., 2004). Similarly, Sema3E is reported to act as an attractant for subiculo-mammilary neurons through Nrp1 but as repellent for corticospinal axons through a Nrp1independent mechanism (Chauvet et al., 2007).

Sema3D or Sema3E can act as repellents in other systems, and the reported finding that Sema3D excludes dorsal retinal axons from the ventral tectum (Liu et al., 2004) raises the possibility that Sema3D and Sema3E are not attractants for retinal axons at the chiasm. They may instead act as repellents that either drive crossing retinal axons into a more permissive pathway on the dorsoventral axis or repel retinal axons that have already reached the midline over to the contralateral side. Repellents have been proposed to channel axons into more permissive pathways. For example, motor axons innervating dorsal limbs are driven away from ventral limb territories by ventrally expressed Ephrin-As, whereas their growth is promoted by dorsally expressed EphAs (Marquardt et al., 2005; Bonanomi and Pfaff, 2010). There is also a compelling precedent for semaphorins acting as repellents that drive axons from the midline to the contralateral side. Spinal commissural axons become sensitive to Sema3B only after crossing the floor plate in which GDNF provides a local signal that prevents calpain-mediated degradation of PlexinA1 (Zou et al., 2000; Charoy et al., 2012). We have not been able to measure either a retraction response or an increase in axon advance when cultured zebrafish retinal axons are exposed to recombinant zebrafish sema3D or sema3E in vitro (data not shown). However, we observe axons extending toward and into patches of cells misexpressing Sema3D or Sema3E in vivo near the chiasm, arguing against a simple repulsive role for either one of them at the midline (data not shown).
These studies were motivated by the hypothesis that GPCRs act as axonal guidance receptors in vivo. Instead, in the retinotectal projection at least, our findings demonstrate an indirect effect of G-protein-coupled signaling in regulating the canonical axonal guidance receptor Nrp1. We conclude that elevated levels of cAMP induce elevated levels of Nrpla and Nrplb in RGCs, that Nrp1 is required for retinal axons to interact with Sema3D, Sema3E, and potentially other signals expressed at the midline, and that this interaction promotes retinal midline crossing. We further propose that activation of GPCRs or other signaling pathways that control cAMP levels have the more general ability to regulate the expression of axonal guidance receptors. This suggests that, as growth cones advance, they can respond to localized signals that regulate cAMP levels and are thereby reprogrammed to respond differently to the next guidance cues they encounter in their environment.

\section{References}

Bae S, Reid CD, Kessler DS (2011) Siamois and Twin are redundant and essential in formation of the Spemann organizer. Dev Biol 352:367-381. CrossRef Medline

Balciunas D, Wangensteen KJ, Wilber A, Bell J, Geurts A, Sivasubbu S, Wang X, Hackett PB, Largaespada DA, McIvor RS, Ekker SC (2006) Harnessing a high cargo-capacity transposon for genetic applications in vertebrates. PLoS Genet 2:e169. CrossRef Medline

Barresi MJ, Hutson LD, Chien CB, Karlstrom RO (2005) Hedgehog regulated Slit expression determines commissure and glial cell position in the zebrafish forebrain. Development 132:3643-3656. CrossRef Medline

Berndt JD, Halloran MC (2006) Semaphorin 3d promotes cell proliferation and neural crest cell development downstream of TCF in the zebrafish hindbrain. Development 133:3983-3992. CrossRef Medline

Bleul CC, Farzan M, Choe H, Parolin C, Clark-Lewis I, Sodroski J, Springer TA (1996) The lymphocyte chemoattractant SDF-1 is a ligand for LESTR/fusin and blocks HIV-1 entry. Nature 382:829-833. CrossRef Medline

Boehmler W, Petko J, Woll M, Frey C, Thisse B, Thisse C, Canfield VA, Levenson R (2009) Identification of zebrafish A2 adenosine receptors and expression in developing embryos. Gene Expr Patterns 9:144-151. CrossRef Medline

Bonanomi D, Pfaff SL (2010) Motor axon pathfinding. Cold Spring Harb Perspect Biol 2:a001735. CrossRef Medline

Bonnin A, Torii M, Wang L, Rakic P, Levitt P (2007) Serotonin modulates the response of embryonic thalamocortical axons to netrin-1. Nat Neurosci 10:588-597. CrossRef Medline

Bouchard JF, Moore SW, Tritsch NX, Roux PP, Shekarabi M, Barker PA, Kennedy TE (2004) Protein kinase A activation promotes plasma membrane insertion of DCC from an intracellular pool: a novel mechanism regulating commissural axon extension. J Neurosci 24:3040-3050. CrossRef Medline

Bovenkamp DE, Goishi K, Bahary N, Davidson AJ, Zhou Y, Becker T, Becker CG, Zon LI, Klagsbrun M (2004) Expression and mapping of duplicate neuropilin-1 and neuropilin-2 genes in developing zebrafish. Gene Expr Patterns 4:361-370. CrossRef Medline

Brend T, Holley SA (2009) Zebrafish whole mount high-resolution double fluorescent in situ hybridization. J Vis Exp pii:1229. CrossRef Medline

Burrill JD, Easter SS Jr (1994) Development of the retinofugal projections in the embryonic and larval zebrafish (Brachydanio rerio). J Comp Neurol 346:583-600. CrossRef Medline

Campbell DS, Regan AG, Lopez JS, Tannahill D, Harris WA, Holt CE (2001) Semaphorin $3 \mathrm{~A}$ elicits stage-dependent collapse, turning, and branching in Xenopus retinal growth cones. J Neurosci 21:8538-8547. Medline

Carlezon WA Jr, Duman RS, Nestler EJ (2005) The many faces of CREB. Trends Neurosci 28:436-445. CrossRef Medline

Chalasani SH, Sabelko KA, Sunshine MJ, Littman DR, Raper JA (2003) A chemokine, SDF-1, reduces the effectiveness of multiple axonal repellents and is required for normal axon pathfinding. J Neurosci 23:1360-1371. Medline

Chalasani SH, Sabol A, Xu H, Gyda MA, Rasband K, Granato M, Chien CB, Raper JA (2007) Stromal cell-derived factor-1 antagonizes slit/robo signaling in vivo. J Neurosci 27:973-980. CrossRef Medline 
Chang LL, Kessler DS (2010) Foxd3 is an essential Nodal-dependent regulator of zebrafish dorsal mesoderm development. Dev Biol 342:39-50. CrossRef Medline

Charoy C, Nawabi H, Reynaud F, Derrington E, Bozon M, Wright K, Falk J, Helmbacher F, Kindbeiter K, Castellani V (2012) gdnf activates midline repulsion by semaphorin3B via NCAM during commissural axon guidance. Neuron 75:1051-1066. CrossRef Medline

Chauvet S, Cohen S, Yoshida Y, Fekrane L, Livet J, Gayet O, Segu L, Buhot MC, Jessell TM, Henderson CE, Mann F (2007) Gating of Sema3E/PlexinD1 signaling by neuropilin- 1 switches axonal repulsion to attraction during brain development. Neuron 56:807-822. CrossRef Medline

Chesler AT, Zou DJ, Le Pichon CE, Peterlin ZA, Matthews GA, Pei X, Miller MC, Firestein S (2007) A G protein/cAMP signal cascade is required for axonal convergence into olfactory glomeruli. Proc Natl Acad Sci U S A 104:1039-1044. CrossRef Medline

Christie TL, Starovic-Subota O, Childs S (2006) Zebrafish collapsin response mediator protein (CRMP)-2 is expressed in developing neurons. Gene Expr Patterns 6:193-200.

Daaka Y, Luttrell LM, Lefkowitz RJ (1997) Switching of the coupling of the beta2-adrenergic receptor to different $G$ proteins by protein kinase A. Nature 390:88-91. CrossRef Medline

Downes GB, Gautam N (1999) The G protein subunit gene families. Genomics 62:544-552. CrossRef Medline

Erskine L, Reijntjes S, Pratt T, Denti L, Schwarz Q, Vieira JM, Alakakone B, Shewan D, Ruhrberg C (2011) VEGF signaling through neuropilin 1 guides commissural axon crossing at the optic chiasm. Neuron 70 : 951-965. CrossRef Medline

Feldner J, Becker T, Goishi K, Schweitzer J, Lee P, Schachner M, Klagsbrun M, Becker CG (2005) Neuropilin-la is involved in trunk motor axon outgrowth in embryonic zebrafish. Dev Dyn 234:535-549. CrossRef Medline

Feldner J, Reimer MM, Schweitzer J, Wendik B, Meyer D, Becker T, Becker CG (2007) PlexinA3 restricts spinal exit points and branching of trunk motor nerves in embryonic zebrafish. J Neurosci 27:4978-4983. CrossRef Medline

Fraser SE, Hunt RK (1980) Retinotectal plasticity in Xenopus: anomalous ipsilateral projection following late larval eye removal. Dev Biol 79:444452. CrossRef Medline

Ghahremani MH, Cheng P, Lembo PM, Albert PR (1999) Distinct roles for Galphai2, Galphai3, and Gbeta gamma in modulation offorskolin- or Gs-mediated cAMP accumulation and calcium mobilization by dopamine D2S receptors. J Biol Chem 274:9238-9245. CrossRef Medline

Gilchrist A, Bünemann M, Li A, Hosey MM, Hamm HE (1999) A dominant-negative strategy for studying roles of $\mathrm{G}$ proteins in vivo. J Biol Chem 274:6610-6616. CrossRef Medline

Gilchrist A, Li A, Hamm HE (2002) G alpha COOH-terminal minigene vectors dissect heterotrimeric G protein signaling. Sci STKE 2002:pl1. Medline

Gordon L, Mansh M, Kinsman H, Morris AR (2010) Xenopus sonic hedgehog guides retinal axons along the optic tract. Dev Dyn 239:2921-2932. CrossRef Medline

Gu C, Rodriguez ER, Reimert DV, Shu T, Fritzsch B, Richards LJ, Kolodkin AL, Ginty DD (2003) Neuropilin-1 conveys semaphorin and VEGF signaling during neural and cardiovascular development. Dev Cell 5:45-57. CrossRef Medline

Hancock ML, Nowakowski DW, Role LW, Talmage DA, Flanagan JG (2011) Type III neuregulin 1 regulates pathfinding of sensory axons in the developing spinal cord and periphery. Development 138:4887-4898. CrossRef Medline

Hendricks M, Jesuthasan S (2007) Electroporation-based methods for in vivo, whole mount and primary culture analysis of zebrafish brain development. Neural Dev 2:6. CrossRef Medline

Huber AB, Kolodkin AL, Ginty DD, Cloutier JF (2003) Signaling at the growth cone: ligand-receptor complexes and the control of axon growth and guidance. Annu Rev Neurosci 26:509-563. CrossRef Medline

Hutson LD, Chien CB (2002) Pathfinding and error correction by retinal axons: the role of astray/robo2. Neuron 33:205-217. CrossRef Medline

Imai T, Suzuki M, Sakano H (2006) Odorant receptor-derived cAMP signals direct axonal targeting. Science 314:657-661. CrossRef Medline

Kay JN, Finger-Baier KC, Roeser T, Staub W, Baier H (2001) Retinal ganglion cell genesis requires lakritz, a zebrafish atonal homolog. Neuron 30:725-736. CrossRef Medline

Kimmel CB, Ballard WW, Kimmel SR, Ullmann B, Schilling TF (1995)
Stages of embryonic development of the zebrafish. Dev Dyn 203:253-310. CrossRef Medline

Klein PS, Sun TJ, Saxe CL 3rd, Kimmel AR, Johnson RL, Devreotes PN (1988) A chemoattractant receptor controls development in Dictyostelium discoideum. Science 241:1467-1472. CrossRef Medline

Knaut H, Werz C, Geisler R, Nüsslein-Volhard C; Tübingen 2000 Screen Consortium (2003) A zebrafish homologue of the chemokine receptor Cxcr4 is a germ-cell guidance receptor. Nature 421:279-282. CrossRef Medline

Koch WJ, Hawes BE, Inglese J, Luttrell LM, Lefkowitz RJ (1994) Cellular expression of the carboxyl terminus of a $\mathrm{G}$ protein-coupled receptor kinase attenuates G beta gamma-mediated signaling. J Biol Chem 269: 6193-6197. Medline

Krechowec SO, Burton KL, Newlaczyl AU, Nunn N, Vlatković N, Plagge A (2012) Postnatal changes in the expression pattern of the imprinted signalling protein XL $\alpha$ s underlie the changing phenotype of deficient mice. PloS One 7:e29753. CrossRef Medline

Kreibich TA, Chalasani SH, Raper JA (2004) The neurotransmitter glutamate reduces axonal responsiveness to multiple repellents through the activation of metabotropic glutamate receptor 1. J Neurosci 24: 7085-7095. CrossRef Medline

Kuwajima T, Yoshida Y, Takegahara N, Petros TJ, Kumanogoh A, Jessell TM, Sakurai T, Mason C (2012) Optic chiasm presentation of Semaphorin6D in the context of Plexin-Al and Nr-CAM promotes retinal axon midline crossing. Neuron 74:676-690. CrossRef Medline

Lakhina V, Marcaccio CL, Shao X, Lush ME, Jain RA, Fujimoto E, Bonkowsky JL, Granato M, Raper JA (2012) Netrin/DCC signaling guides olfactory sensory axons to their correct location in the olfactory bulb. J Neurosci 32:4440-4456. CrossRef Medline

Lankford KL, DeMello FG, Klein WL (1988) D1-type dopamine receptors inhibit growth cone motility in cultured retina neurons: evidence that neurotransmitters act as morphogenic growth regulators in the developing central nervous system. Proc Natl Acad Sci U S A 85:4567-4571. Medline

Lee P, Goishi K, Davidson AJ, Mannix R, Zon L, Klagsbrun M (2002) Neuropilin-1 is required for vascular development and is a mediator of VEGF-dependent angiogenesis in zebrafish. Proc Natl Acad Sci U S A 99:10470-10475. Medline

Li Q, Shirabe K, Thisse C, Thisse B, Okamoto H, Masai I, Kuwada JY (2005) Chemokine signaling guides axons within the retina in zebrafish. J Neurosci 25:1711-1717. CrossRef Medline

Li T, Vu TH, Zeng ZL, Nguyen BT, Hayward BE, Bonthron DT, Hu JF, Hoffman AR (2000) Tissue-specific expression of antisense and sense transcripts at the imprinted Gnas locus. Genomics 69:295-304. CrossRef Medline

Liu Y, Berndt J, Su F, Tawarayama H, Shoji W, Kuwada JY, Halloran MC (2004) Semaphorin3D guides retinal axons along the dorsoventral axis of the tectum. J Neurosci 24:310-318. CrossRef Medline

Lonze BE, Ginty DD (2002) Function and regulation of CREB family transcription factors in the nervous system. Neuron 35:605-623. CrossRef Medline

Lonze BE, Riccio A, Cohen S, Ginty DD (2002) Apoptosis, axonal growth defects, and degeneration of peripheral neurons in mice lacking CREB. Neuron 34:371-385. CrossRef Medline

Marquardt T, Shirasaki R, Ghosh S, Andrews SE, Carter N, Hunter T, Pfaff SL (2005) Coexpressed EphA receptors and ephrin-A ligands mediate opposing actions on growth cone navigation from distinct membrane domains. Cell 121:127-139. CrossRef Medline

Mora-Ferrer C, Yazulla S, Studholme KM, Haak-Frendscho M (1999) Dopamine D1-receptor immunolocalization in goldfish retina. J Comp Neurol 411:705-714. Medline

Moore SW, Kennedy TE (2006) Protein kinase A regulates the sensitivity of spinal commissural axon turning to netrin-1 but does not switch between chemoattraction and chemorepulsion. J Neurosci 26:2419-2423. CrossRef Medline

Mullins MC, Hammerschmidt M, Haffter P, Nüsslein-Volhard C (1994) Large-scale mutagenesis in the zebrafish: in search of genes controlling development in a vertebrate. Curr Biol 4:189-202. CrossRef Medline

Nawabi H, Briançon-Marjollet A, Clark C, Sanyas I, Takamatsu H, Okuno T, Kumanogoh A, Bozon M, Takeshima K, Yoshida Y, Moret F, Abouzid K, Castellani V (2010) A midline switch of receptor processing regulates 
commissural axon guidance in vertebrates. Genes Dev 24:396-410. CrossRef Medline

Novotny J, Svoboda P (1998) The long (Gs(alpha)-L) and short (Gs(alpha)-S) variants of the stimulatory guanine nucleotide-binding protein. Do they behave in an identical way? J Mol Endocr 20:163-173. CrossRef Medline

O'Donnell M, Chance RK, Bashaw GJ (2009) Axon growth and guidance: receptor regulation and signal transduction. Annu Rev Neurosci 32:383412. CrossRef Medline

Oka Y, Korsching SI (2011) Shared and unique G alpha proteins in the zebrafish versus mammalian senses of taste and smell. Chem Senses 36: 357-365. CrossRef Medline

Oldham WM, Hamm HE (2006) Structural basis of function in heterotrimeric $G$ proteins. Q Rev Biophys 39:117-166. CrossRef Medline

Oldham WM, Hamm HE (2008) Heterotrimeric G protein activation by G-protein-coupled receptors. Nat Rev Mol Cell Biol 9:60-71. CrossRef Medline

Palaisa KA, Granato M (2007) Analysis of zebrafish sidetracked mutants reveals a novel role for Plexin A3 in intraspinal motor axon guidance. Development 134:3251-3257. CrossRef Medline

Pasterkamp RJ (2012) Getting neural circuits into shape with semaphorins. Nat Rev Neurosci 13:605-618. CrossRef Medline

Pittman AJ, Law MY, Chien CB (2008) Pathfinding in a large vertebrate axon tract: isotypic interactions guide retinotectal axons at multiple choice points. Development 135:2865-2871. CrossRef Medline

Pond A, Roche FK, Letourneau PC (2002) Temporal regulation of neuropilin-1 expression and sensitivity to semaphorin $3 \mathrm{~A}$ in NGF- and NT3-responsive chick sensory neurons. J Neurobiol 51:43-53. CrossRef Medline

Poulain FE, Gaynes JA, Stacher Hörndli C, Law MY, Chien CB (2010) Analyzing retinal axon guidance in zebrafish. Methods Cell Biol 100:3-26. CrossRef Medline

Robu ME, Larson JD, Nasevicius A, Beiraghi S, Brenner C, Farber SA, Ekker SC (2007) p53 activation by knockdown technologies. PLoS Genet 3:e78. CrossRef Medline

Rudolph D, TafuriA, Gass P, Hämmerling GJ, Arnold B, Schütz G (1998) Impaired fetal $\mathrm{T}$ cell development and perinatal lethality in mice lacking the cAMP response element binding protein. Proc Natl Acad Sci U S A 95:4481-4486. CrossRef Medline

Sakai JA, Halloran MC (2006) Semaphorin 3d guides laterality of retinal ganglion cell projections in zebrafish. Development 133:1035-1044. CrossRef Medline

Sánchez-Camacho C, Bovolenta P (2008) Autonomous and nonautonomous Shh signalling mediate the in vivo growth and guidance of mouse retinal ganglion cell axons. Development 135:3531-3541. CrossRef Medline

Sands WA, Palmer TM (2008) Regulating gene transcription in response to cyclic AMP elevation. Cell Signal 20:460-466. CrossRef Medline

Schwarz Q, Waimey KE, Golding M, Takamatsu H, Kumanogoh A, Fujisawa $\mathrm{H}$, Cheng HJ, Ruhrberg C (2008) Plexin A3 and plexin A4 convey semaphorin signals during facial nerve development. Dev Biol 324:1-9. CrossRef Medline
Scott EK, Baier H (2009) The cellular architecture of the larval zebrafish tectum, as revealed by gal 4 enhancer trap lines. Front Neural Circuits 3:13. CrossRef Medline

Selkirk JV, Price GW, Nahorski SR, Challiss RA (2001) Cell type-specific differences in the coupling of recombinant mGlulalpha receptors to endogenous G protein sub-populations. Neuropharmacology 40:645-656. CrossRef Medline

Sharma A, Verhaagen J, Harvey AR (2012) Receptor complexes for each of the Class 3 Semaphorins. Front Cell Neurosci 6:28. CrossRef Medline

Shewan D, Dwivedy A, Anderson R, Holt CE (2002) Age-related changes underlie switch in netrin-1 responsiveness as growth cones advance along visual pathway. Nat Neurosci 5:955-962. CrossRef Medline

Shoji W, Isogai S, Sato-Maeda M, Obinata M, Kuwada JY (2003) Semaphorin3al regulates angioblast migration and vascular development in zebrafish embryos. Development 130:3227-3236. CrossRef Medline

Tessier-Lavigne M, Goodman CS (1996) The molecular biology of axon guidance. Science 274:1123-1133. CrossRef Medline

Torres-Vázquez J, Gitler AD, Fraser SD, Berk JD, Van N Pham, Fishman MC, Childs S, Epstein JA, Weinstein BM (2004) Semaphorin-plexin signaling guides patterning of the developing vasculature. Dev Cell 7:117-123. CrossRef Medline

Twery EN, Raper JA (2011) SDF1-induced antagonism of axonal repulsion requires multiple G-protein coupled signaling components that work in parallel. PloS One 6:e18896. CrossRef Medline

Vetter ML, Brown NL (2001) The role of basic helix-loop-helix genes in vertebrate retinogenesis. Semin Cell Dev Biol 12:491-498. CrossRef Medline

Wolman MA, Liu Y, Tawarayama H, Shoji W, Halloran MC (2004) Repulsion and attraction of axons by semaphorin $3 \mathrm{D}$ are mediated by different neuropilins in vivo. J Neurosci 24:8428-8435. CrossRef Medline

Wong ST, Trinh K, Hacker B, Chan GC, Lowe G, Gaggar A, Xia Z, Gold GH, Storm DR (2000) Disruption of the type III adenylyl cyclase gene leads to peripheral and behavioral anosmia in transgenic mice. Neuron 27:487497. CrossRef Medline

Xiang Y, Li Y, Zhang Z, Cui K, Wang S, Yuan XB, Wu CP, Poo MM, Duan S (2002) Nerve growth cone guidance mediated by G protein-coupled receptors. Nat Neurosci 5:843-848. CrossRef Medline

Xu H, Leinwand SG, Dell AL, Fried-Cassorla E, Raper JA (2010) The calmodulin-stimulated adenylate cyclase ADCY8 sets the sensitivity of zebrafish retinal axons to midline repellents and is required for normal midline crossing. J Neurosci 30:7423-7433. CrossRef Medline

Yamamizu K, Kawasaki K, Katayama S, Watabe T, Yamashita JK (2009) Enhancement of vascular progenitor potential by protein kinase A through dual induction of Flk-1 and Neuropilin-1. Blood 114:3707-3716. CrossRef Medline

Yu HH, Houart C, Moens CB (2004) Cloning and embryonic expression of zebrafish neuropilin genes. Gene Expr Patterns 4:371-378. CrossRef Medline

Zou Y, Stoeckli E, Chen H, Tessier-Lavigne M (2000) Squeezing axons out of the gray matter: a role for slit and semaphorin proteins from midline and ventral spinal cord. Cell 102:363-375. CrossRef Medline 